\title{
Is Your Vitreous Really Necessary?
}

\section{The role of the vitreous in the eye with particular reference to retinal attachment, detachment and the mode of action of vitreous substitutes}

\author{
W. S. FOULDS
}

Glasgow

No one needs to be reminded of the very great contributions to Óphthalmology made by Duke-Elder not only in his scientific researches but in his writings especially his monumental works, the Textbook of Ophthalmology and the System of Ophthalmology. Duke-Elder's superb skill in the use of the English language is apparent to all in either work. He hated equally linguistic inaccuracy and verbosity, and certainly demonstrated to me on more than one occasion an economy in the use of language which must have been related in some way to his native Scottish thrift.

Duke-Elder was largely responsible at the inception of the National Health Service, for the amalgamation of three famous eye hospitals in London, The Royal London Ophthalmic Hospital, The Royal Westminster Ophthalmic Hospital and the Central Eye Hospital. From the amalgamation grew the Institute of Ophthalmology and the development of Moorfields as a great teaching hospital. Moorfields of course existed long before Duke-Elder but it was Duke-Elder's vision and foresight that saw the need to amalgamate relatively small hospitals into an organisation which was large enough to remain independent within the National Health Service, and in this way paved the way for the pre-eminence which Moorfields holds in ophthalmo- logical practice and training in the United Kingdom.

'The Duke' as everyone at the Institute knew him, not only encouraged and stimulated research but took a real personal interest in what everyone in the Institute was doing. The high standing of the Institute internationally was a direct result of his enthusiasm, hard work, scientific acumen and administrative skill. Above all Sir Stewart was a warm human being. Many years ago I was proud to work under his guidance in the Institute and today I am more than ever proud to honour his memory.

The title of this lecture may sound flippant but it was prompted by the thought that not only have we no generally agreed views on why we have a vitreous, but now treat it with scant respect as something to be removed when it gets in the way without asking if it is performing any useful function.

Nowhere are possible functions of the vitreous of more relevance than in relation to retinal attachment or detachment, a subject which has intrigued me for most of my professional career. Most ophthalmologists imagine that the retina is rather precariously attached to its bed and liable to detach under very little provocation whereas in reality the opposite is probably true, the retina is held in place by relatively strong mechanical and functional

Correspondence to: Wallace S. Foulds, Tennent Institute of Ophthalmology, University of Glasgow, Western Infirmary, 38 Church Street, Glasgow G11 6NT.

Based on the 2nd Duke-Elder Foundation Lecture delivered in the University of London, January 1986 and containing material included in the Estelle Doheny Lecture delivered in the Estelle Doheny Foundation, Los Angeles, December 1985. 
forces and detachment of the retina indicates a failure of many factors and not just one.

More and more the retina surgeon starts his operation whether it be for retinal detachment or the restoration of a light path in an eye with a vitreous haemorrhage, by carrying out a vitrectomy. Vitrectomies are used to relieve intraocular traction, to remove vitreous opacities, to modify intraocular cellular proliferation and as a useful way of controlling the intraocular volume in tumour surgery.

I have been resecting choroidal melanomas locally for more than 15 years $^{1-3}$ (Fig. 1) but the techniques are still evolving. A recent modification which has proved very helpful has been to start the operation with a closed pars plana vitrectomy so that the vitreous is replaced with saline. This allows rapid changes of volume as dictated by the needs of the subsequent procedure. Thus during dissection of the scleral flap the intraocular pressure is elevated and the eye wall rendered firm for lamellar dissection by a suitable position-
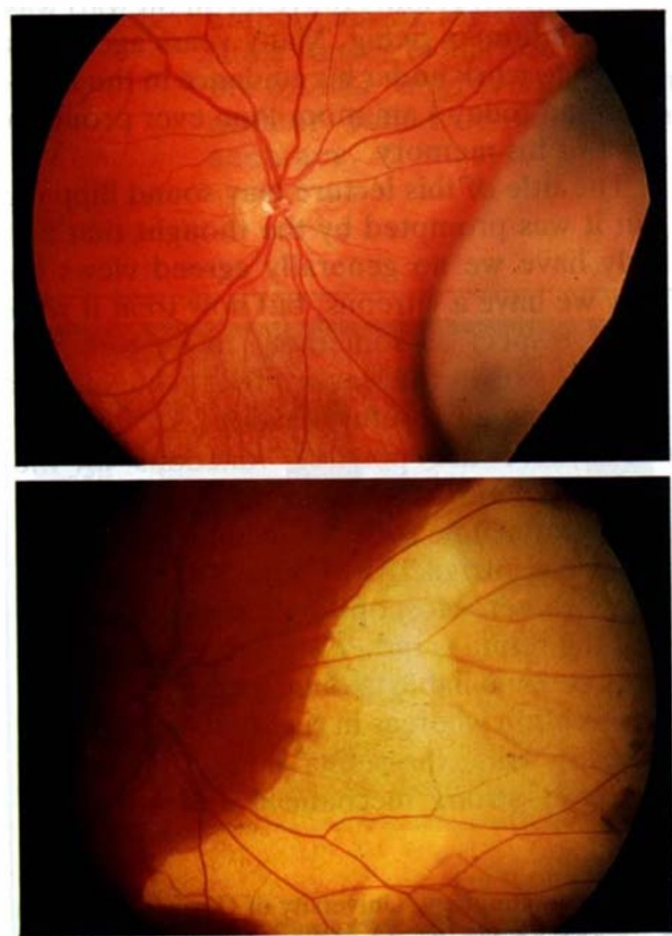

Fig. 1. Local resection of choroidal melanoma, (a) pre-operative appearance, (b) post-operative appearance. ing of the reservoir. During the actual dissection of the tumour and its removal from the eye the intraocular volume can be greatly reduced by withdrawing fluid from the vitreous cavity with a syringe attached to a 3-way tap in the infusion line. At the end of the procedure the relatively collapsed globe can be reinflated either with saline from the reservoir or by gas injection by way of the 3-way tap. The ability to change the volume of the posterior segment of the eye dramatically and rapidly has greatly aided this form of surgery. Such rapid changes cannot be made in the presence of an intact vitreous and this immediately suggests one possible role for the vitreous - that of stabilising the volume of the globe and resisting rapid changes in size.

We know that the vitreous has a complex structure of collagen fibrils stabilised by molecules of a high molecular weight hydrophilic polymer-a complex sugar-a glycosaminoglycan, hyaluronic acid. ${ }^{4,5}$ Glycosaminoglycans are important components of the extra-cellular matrix in many tissues. They are linear polymers of repeating disaccharide units and with the exception of hyaluronic acid tend not to occur as free polymers, but as proteoglycans linked to a protein core. Glycosaminoglycans can interact with other proteins such as collagen to form links between collagen molecules. ${ }^{6,7}$

Although highly viscous, hyaluronic acid is soluble and highly hydrophilic giving the vitreous its gel-like structure with both viscous and visco-elastic properties. ${ }^{5}$

The entangled gel-like nature of the polysaccharide traps water in the domain of the molecule making it not only retentive of water, but capable of modifying water movement through it ${ }^{8,9}$ Not only does the remarkable water binding capacity of the hyaluronic acid in the vitreous give optical clarity but in addition prevents rapid movement of water out of or into the vitreous body so that the hyaluronic acid of the vitreous may be thought of as a damping mechanism capable of resisting rapid changes of volume of the globe. At its most obvious the presence of an intact vitreous will act as a mainline defence against collapse of the globe should it be perforated.

A manipulation commonly used in cataract surgery particularly in the United States of 
America is pre-operative massage or compression of the globe ostensibly to reduce the intraocular pressure. As soon as the eye is opened however the intraocular pressure is of course effectively at atmospheric pressure and any advantage conveyed by ocular compression in terms of intraocular pressure is lost. It is possible however that the manoeuvre redistributes some of the intraocular fluid expressing it from the vitreous and so reducing vitreous volume with some benefit in terms of surgical access and safety. In my own mind any such advantage is likely to be outweighed by a compensatory vasodilatation in the choroid which will tend to counteract any reduction of volume in the posterior segment of the eye and may carry additional disadvantages.

As a slight diversion it is interesting to look at other sites in the eye containing glycosaminoglycans and glycoproteins. These include the stroma of the cornea, the extracellular spaces of the trabecular meshwork and the subretinal tissue spaces filled by the inter-photoreceptor matrix. ${ }^{10-14}$

Is the water binding capacity of the ground substance important in the cornea? We know that corneal transparency is very dependent on its water content ${ }^{15}$ and on the exact separation of the collagen fibrils which make up the stroma (Fig. 2). Any change in interfibrillary distance has an immediate deleterious effect on corneal light transmission and nowadays we are all aware of the crucial role played by

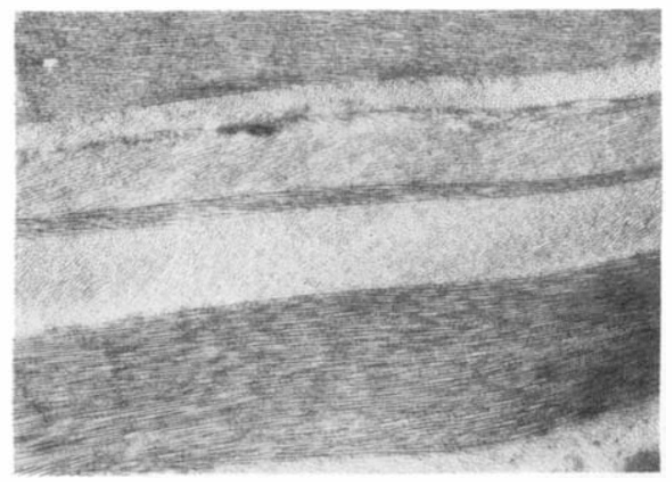

Fig. 2. Transmission electronmicrograph of normal corneal stroma to show the regular arrangement of collagen fibrils separated by an exact interval designed to promote maximum light transmission. The dimensions of this interval may be maintained by the glycosaminoglycan ground substance $(\times 13,000)$. the corneal endothelium in maintaining the required state of deturgesence of the cornea. ${ }^{16}$ Physically it would be difficult for the appropriate fibrillar separation in the stroma to be constantly maintained without some mechanism preventing short term local changes in hydration and in the ground substance of the cornea we have just such a mechanism. ${ }^{17-19}$ It is easy to conceive of the corneal turgesence as a balance between the swelling pressure of the ground substance and the dehydrating efforts of the endothelium. Soft contact lenses lacking this mechanism are notably prone to short term changes in hydration and of focus when the relative humidity of the atmosphere changes.

An aspect of the action of glycosaminoglycans which is important to consider, is their viscosity and their influence on cellular and molecular movement. In the trabecular tissue the resistance to aqueous outflow can be modified by perfusing the anterior chamber with hyaluronidase,,$^{20-23}$ and the glycosaminoglycans in the trabecular tissue make an as yet incompletely quantified contribution to the resistance to aqueous outflow through the trabecular meshwork ${ }^{24-29}$ (Fig. 3).

Returning to the vitreous we know that not only is its structure complex at the molecular level but in addition there are great variations in structure within the vitreous cavity, the highest concentration of hyaluronic acid and of collagen being in the cortical vitreous next to the retina and of course at the vitreous base, while the lowest concentrations are in the mid-vitreous ${ }^{5}$ (Fig. 4).

We know that in the normal eye most of the aqueous that is formed passes into the anterior chamber and is cleared from the eye by way of the Canal of Schlemm under the action of the hydrostatic pressure difference that exists between the anterior chamber and the episcleral venous plexus. In primates up to 20 per cent of aqueous outflow from the eye is by non-conventional routes. ${ }^{30}$ An important non-conventional route may be the trans-retinal route to the capillaries of the choroid. ${ }^{31}$ Experiments with tritiated water injected into the mid-vitreous have shown that water from there is largely cleared to the choroid across the intact retina, more than 88 per cent of injected water leaving the eye by this route 

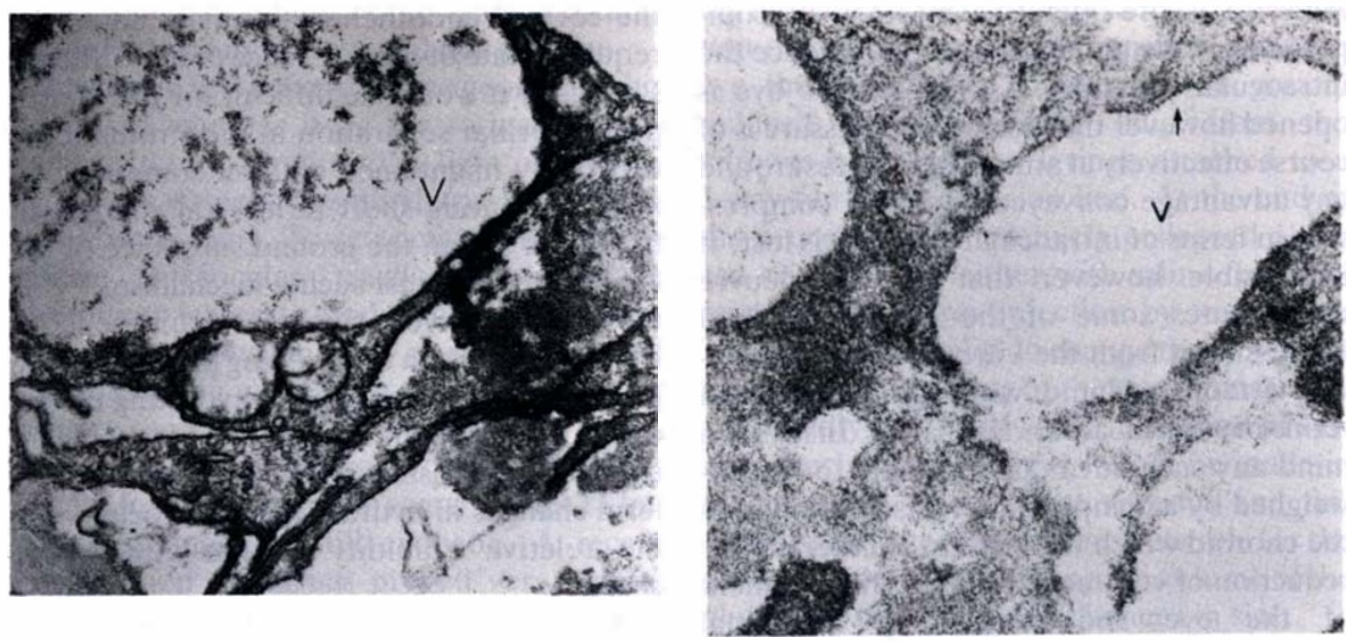

Fig. 3. Transmission electronmicrograph of the human outflow apparatus stained with colloidal iron for glycosaminoglycans. Glycosaminoglycans are abundant in normal trabecular tissue (a) but markedly depleted after perfusion with hyaluronidase $(a)(\times 11,500)(b)(\times 6,500)$. (Preparation of $P$. McMenamin). $(V=$ giant vacuole.)
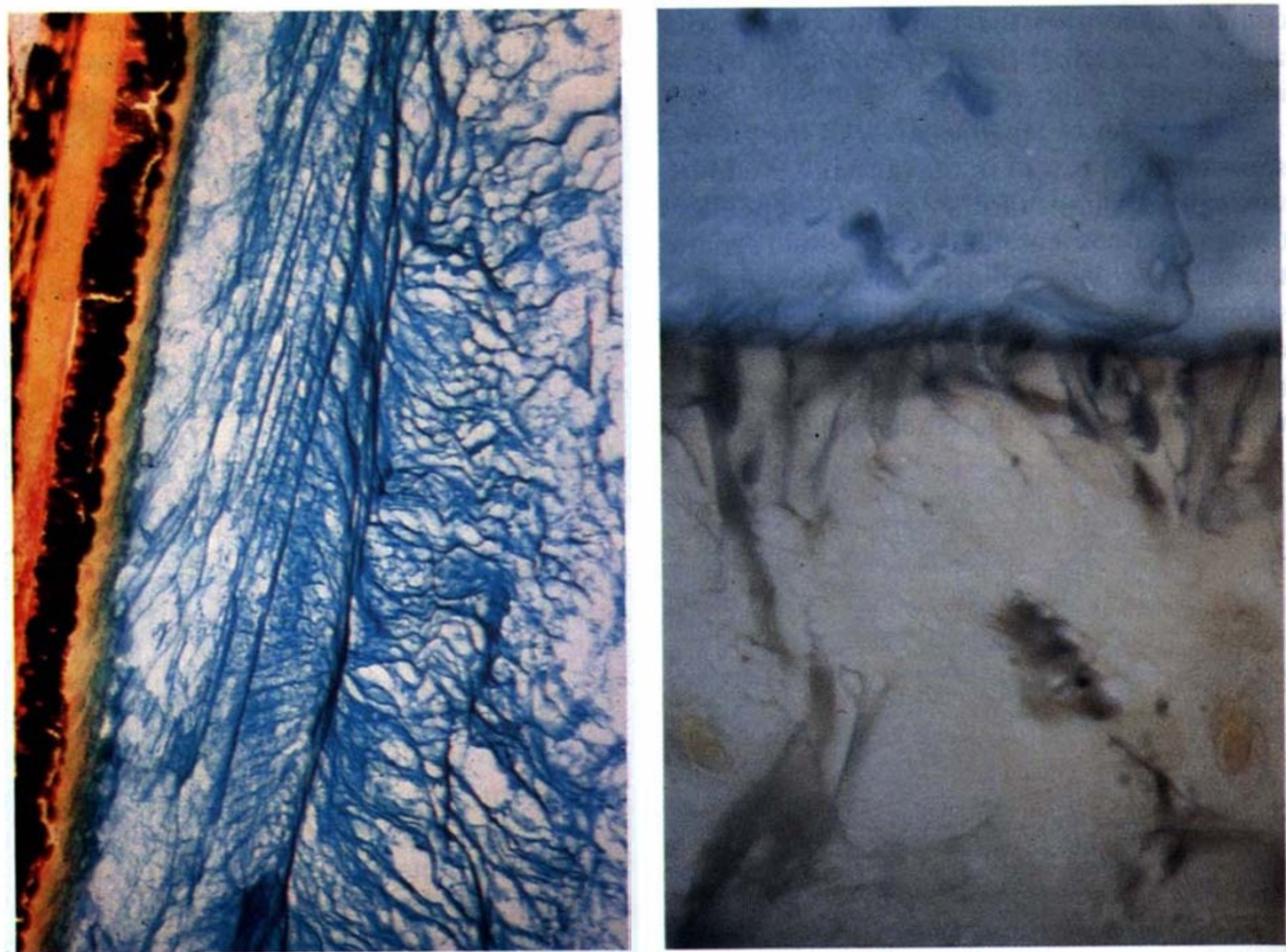

Fig. 4. Normal vitreous from the vitreous base (a) and from the cortical vitreous close to the equatorial retina (b) stained with the coloidal iron and the prussian blue reaction for glycosaminoglycans. The heavy staining and coarse fibrillar structure of the vitreous base is evident as is the increased concentration of glycosaminoglycan in the cortical as against the non cortical vitreous $((a) \times 100,(b) \times 800)$. (Preparation of N. Johnson.) 
and only 3 per cent leaving the vitreous by way of the anterior chamber in the phakic eye ${ }^{32}$ (Fig. 5). Vitreous fluorophotometry has demonstrated that the outward clearance of fluorescein from the vitreous to the bloodstream greatly exceeds any inward movement from the choroid to the vitreous. ${ }^{33-36}$

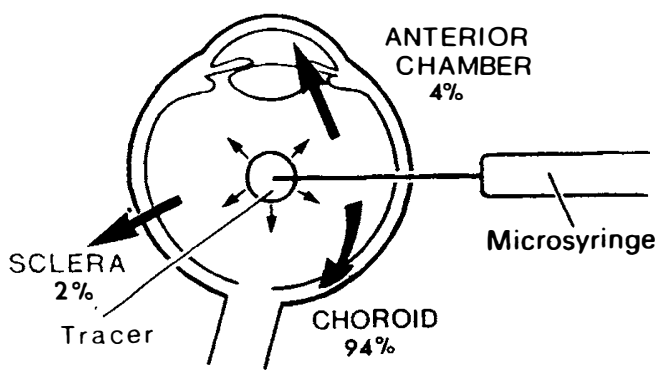

Fig. 5. Diagram to illustrate routes of clearance of intravitreally injected tritiated water. Most of the tracer is cleared posteriorly across the intact retina and RPE to the choroid.

It is difficult to assess what proportion of aqueous secreted by the ciliary body enters the vitreous rather than the anterior chamber but it seems likely that the major part of that portion of the aqueous inflow which diffuses into the vitreous cavity is subsequently cleared posteriorly across the retina and RPE to the choroid.

The low rate of clearance of water or fluorescein from the vitreous to the anterior chamber $^{37}$ is probably related to the small surface area available for diffusional exchange around the lens an area which would be increased in the aphakic eye. The forward clearance of water from the vitreous cavity is likely to be increased even more in the aphakic vitrectomised eye. There is a possibility that a change in the relative amounts of intraocular fluid (including angiogenic factors) being cleared from the eye anteriorly via the Canal of Schlemm and posteriorly across the retina could be of profound significance in relation to the high incidence of anterior segment neovascularisation following vitrectomy and lensectomy in diabetic eyes.

An alteration in the relative volumes of secreted aqueous cleared anteriorly and posteriorly after cataract extraction could also conceivably be of significance in relation to aphakic cystoid macular oedema. It is a generally held view that the incidence of cystoid macular oedema is greater after intracapsular than extracapsular extraction.

Does the presence of an intact vitreous influence water movement in the posterior segment of the eye? Solutions of hyaluronic acid especially if stabilised on a suitable substrate can significantly impede water movement $^{8,38}$ and as we have shown ${ }^{39}$ depolymerisation of the hyaluronic acid of the vitreous by the injection of hyaluronidase significantly increases the rate of clearance of tritiated water from the mid-vitreous to the choroid. In addition tracers introduced into the vitreous cavity disappear more rapidly from vitrectomised eyes than from eyes with an intact vitreous. ${ }^{40,41}$

Other experiments have shown that hyaluronic acid can impede the movement of larger molecules such as peptides and of cells. $^{42-44}$. There is little doubt that the intact cortical vitreous can not only limit the rate of water movement through it but act as a barrier to the ingress into the vitreous cavity of unwanted molecules or cells.

\section{Retinal Apposition}

What are the factors which maintain retinal apposition? They can conveniently be divided into passive or structural factors and active forces. ${ }^{45,46}$ Among the former one can list the structural integrity of the retina itself, the close interdigitation of retinal receptor cell outer segments with the apical processes of the pigment epithelium (Fig. 6) and the presence between the pigment epithelium and the receptor cells of the interphotoreceptor matrix (Fig. 7). Active forces important in retinal apposition result from those mechanisms that ensure that fluid does not accumulate in the potential subretinal space.

As already indicated there is considerable evidence that water secreted into the vitreous cavity from the ciliary body largely leaves the eye by a trans-retinal, trans-RPE route and our experiments in rabbit eyes have shown that the mean time taken by a molecule of water to leave the eye by way of the choroid is around 32 minutes and that roughly half the water in the vitreous passes to the choroid each 36 minutes. ${ }^{37}$ The retina is therefore rela- 


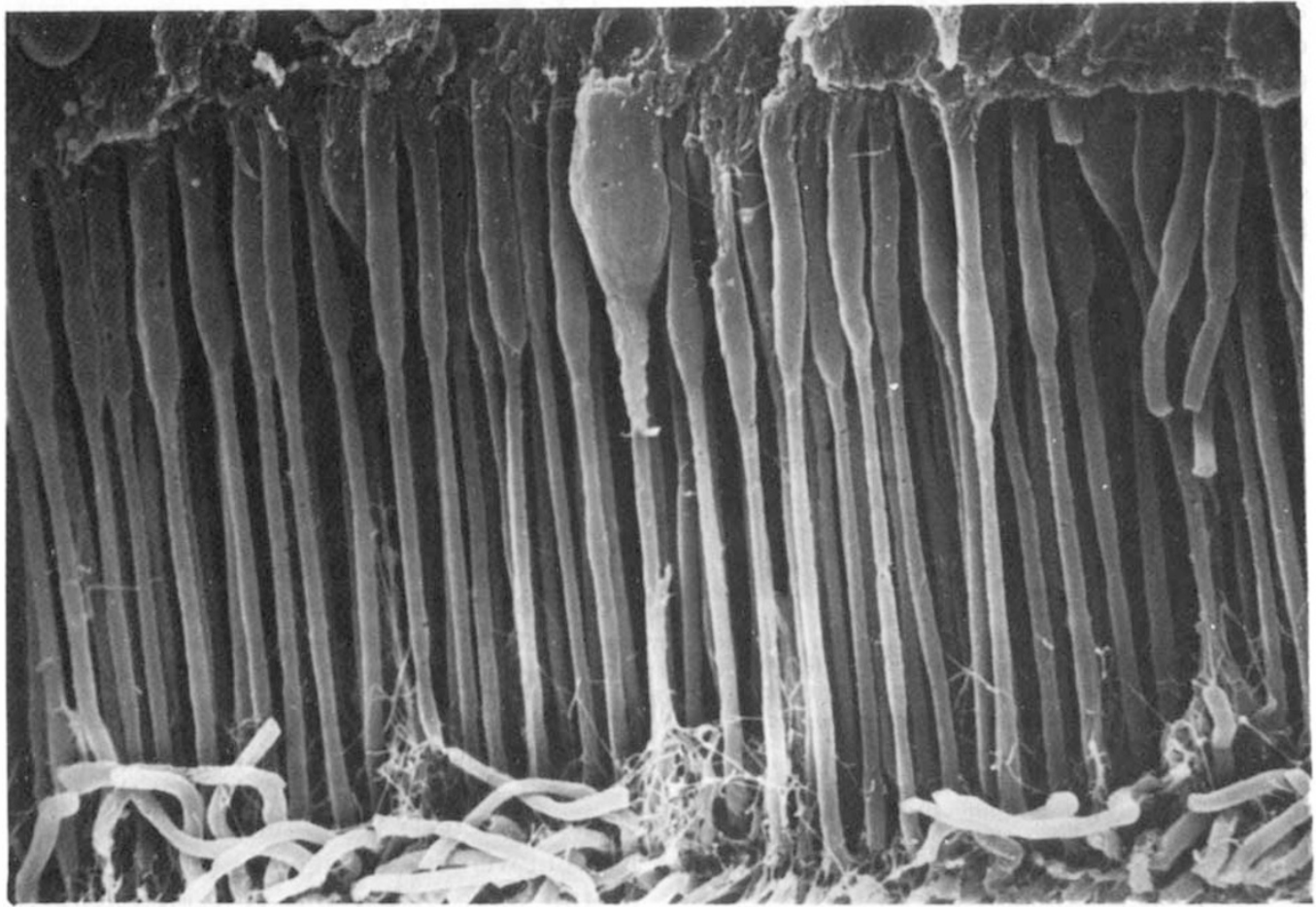

Fig. 6. Scanning electronmicrograph of human receptor cell outer segments interdigitating with the apical processes of the retinal pigment epithelium $(\times 3,500)$.

tively permeable to water although it does have a measurable flow resistance which we and others have measured. ${ }^{47,48}$

Although water can pass readily through the intact retina, under normal conditions, it does not accumulate in the subretinal space so there must be a mechanism for removing water from the potential subretinal space. Possible mechanisms driving water across the retina and the RPE to the choroid include a hydrostatic pressure difference, the effects of colloid osmotic pressure acting across an intact RPE and active transport by the RPE.

Undoubtedly there is a hydrostatic pressure difference between the vitreous cavity and the orbit but no measurable pressure difference has been detected between the vitreous and the subretinal space. ${ }^{49}$ Anders Bill ${ }^{31}$ was one of the first to suggest that it is the difference between the colloid osmotic pressure of the blood and the vitreous which draws water across the retina and the RPE towards the choroid. We know that the fenestrated capillaries of the choroid leak plasma protein into the extravascular tissue spaces of the choroid and that this protein-containing fluid can pass through Bruch's membrane to bathe the outer aspects and lateral clefts of the RPE cells. We know too that the RPE with its apical tight occluding junctions is a complete barrier to the inward movement of plasma proteins and other molecules. ${ }^{50-53}$ As the retina is relatively permeable to water the subretinal space even in the presence of an intact retina is in continuity with the water in the vitreous cavity.

Water in the potential subretinal space which has passed across the intact retina from the vitreous cavity by diffusion or has originated in the retinal capillaries is separated from the protein-rich extravascular fluid on the outer side of the RPE cells by the cell membranes of the RPE and their zonular adhesions (Fig. 8). The separation of a relatively non-protein containing fluid from one containing significant quantities of soluble protein by a membrane which is permeable to water but not to protein will result in a colloid osmotic pressure gradient across the RPE so 


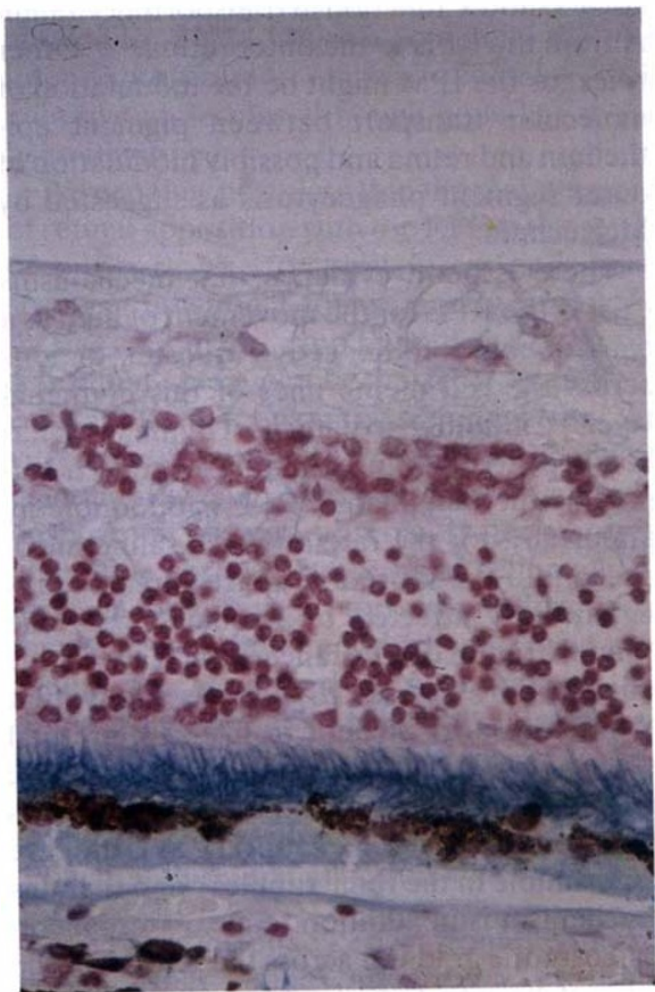

Fig. 7. Light micrograph to show the interphotoreceptor matrix (arrowed) lying between the outer segments of the retinal receptor cells and the RPE (Alcian Blue $\times 350)$. (Preparation by I Grierson.)

that in consequence water will be drawn out of the subretinal space across the RPE to the $\log \left[{ }^{3} \mathrm{H}\right]$ choroid. Such a mechanism would require an intact RPE but no active work on the part of the RPE cells.

How do we know that colloid osmotic pressure is important in keeping the subretinal space empty? Experiments in which fluid was injected under the retina ${ }^{54-56}$ have shown that saline is more rapidly removed from the subretinal space than plasma. ${ }^{57,58}$ In addition it has been shown that the intravitreal injection of hyperosmotic solutions rapidly leads to retinal detachment. ${ }^{59}$ In experiments I have carried out hypervolaemic dilution of the blood by intravenously administered low molecular weight dextran doubled the mean transit time of radio-labelled water from the vitreous to the choroid (Fig. 9). A clinical correlate is a patient I have seen with a protein-losing enteropathy who developed macu-

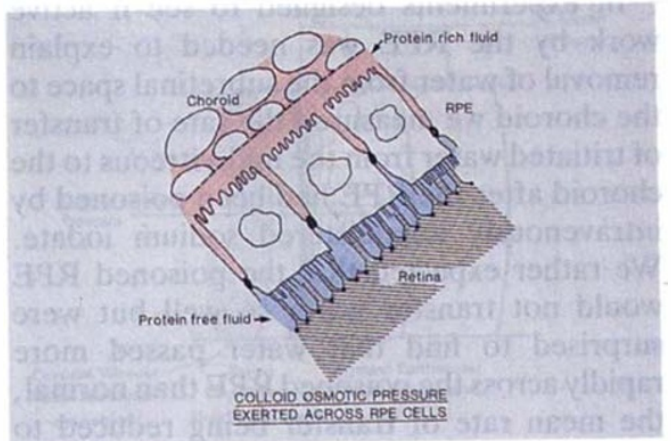

Fig. 8. Diagram of outer retina and RPE. The RPE with its tight junctions is impermeable to protein and separates the extravascular tissue spaces of the choroid which are rich in soluble protein from the subretinal space which has a relatively low content of soluble protein thus creating a colloid osmotic pressure gradient towards the choroid.

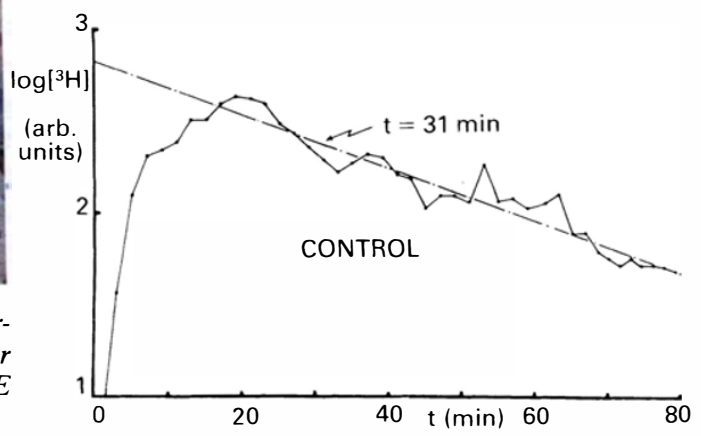

a.

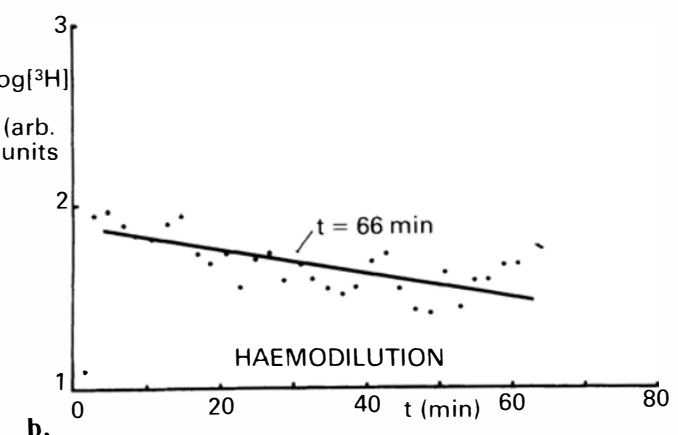
b.

Fig. 9. Diagram to illustrate decreased rate of transfer to the choroid of intravitreally injected tritiated water after hypervolaemic haemodilution. (a) typical control animal, (b) after hypervolaemic haemodilution.

lar oedema and serous retinal detachments when the plasma proteins fell below 3 grammes per cent. The oedema disappeared and acuity recovered when the plasma protein level increased. 
In experiments designed to see if active work by the RPE was needed to explain removal of water from the subretinal space to the choroid we measured the rate of transfer of tritiated water from the mid-vitreous to the choroid after the RPE had been poisoned by intravenously administered sodium iodate. We rather expected that the poisoned RPE would not transfer water so well but were surprised to find that water passed more rapidly across the poisoned RPE than normal, the mean rate of transfer being reduced to $24 \pm 4$ minutes as compared with a control value of $36 \pm 4$ minutes. Marmor too found that saline in the subretinal space disappeared more rapidly if the RPE had been poisoned by sodium iodate. ${ }^{60}$ Marmor suggested that the RPE acted as both a pump and a barrier and that sodium iodate eliminated the former but additionally decreased the latter. An alternative explanation that has not yet been tested is that systemically administered sodium iodate may alter the osmolarity of the blood as well as damaging the RPE. Certainly the experiments show that water can pass readily from the subretinal space to the choroid even when the RPE is non-functional although structurally intact again suggesting the importance of a colloid osmotic pressure gradient across the RPE.

One difficulty in explaining trans-pigment epithelial movement of water on the basis of a colloid osmotic pressure difference between choroid and subretinal space is the presence within the subretinal space of the inter-photoreceptor matrix ${ }^{10,11}$ containing as it does molecules of proteoglycan, glycoprotein and the inter-photoreceptor retinol binding protein..$^{12,13,61,62}$. All of these molecules could generate a colloid osmotic pressure which would act against the colloid osmotic pressure of the choroid and tend to retain water in the subretinal space. Indeed this could be an important role for the glycosaminoglycans of the inter-photoreceptor matrix allowing the maintenance of appropriate dimensions of the metabolically important interval between pigment epithelium and retina which would be necessary if inappropriate local concentrations of metabolites were to be avoided and to allow for example, the inter-photoreceptor retinol binding protein room to exer- cise its shuttle function in transporting vitamin A from the RPE to the outer retina.$^{63,64}$ Other roles for the IPM might be the modulation of molecular transport between pigment epithelium and retina and possibly modulation of outer segment phagocytosis as suggested by McKechnie. ${ }^{65}$

There is good evidence that mechanisms exist in the RPE for the movement of fluid as a consequence of the active transfer of ions across the cell membranes of this epithelial layer ${ }^{66-71}$ although to date most of the work has been carried out in amphibia. Active transport by the mammalian RPE is undoubtedly important, for the rate at which saline introduced ints the subretinal space is removed is significantly affected by hypoxia or by the administration of substances which alter ionic transport by the RPE. ${ }^{72,73}$ It is likely that active transport of fluid from the subretinal space by the RPE is the result of local osmotic gradients generated by ionic transport across the infolded basal cell membrane as is the case for example in the renal tubules ${ }^{74}$ and that this mechanism is in addition to any external colloid osmotic gradient across the RPE. For the sake of brevity I shall refer to both mechanisms together under the term 'pigment epithelial pump' but remembering at the same time that the 'pump' may be partly active and partly passive.

If the RPE pump depends partly on ionic transport by the RPE and on the absence of plasma proteins in the intraocular fluids a change of either of these conditions will reduce the forces maintaining retinal apposition. A focal break in the RPE barrier as is seen in central serous retinopathy will cause a focal breakdown of the mechanisms maintaining retinal apposition and allow the development of a localised retinal detachment. More widespread damage to the RPE such is as seen in some circulatory abnormalities, for example the toxaemia of pregnancy will be associated with a widespread failure of the RPE pump and an extensive although reversible retinal detachment.

Any detachment of the retina from its bed will of course have to overcome structural adhesive forces between the retina and the RPE. The interdigitation of the outer segments of the receptor cells with the apical 
processes of the RPE has already been alluded to. There is also a possibility that the inter-photoreceptor matrix contains cell adhesive molecules although none has so far been identified.

We can thus postulate that the maintenance of retinal apposition with the RPE is the result of rather weak structural forces and much stronger functional forces largely generated by the continuous emptying of the potential subretinal space across the RPE in spite of constant trans-retinal replenishment from the vitreous as illustrated in the accompanying diagram (Fig. 10). Thus water passes continuously from the mid vitreous to the choroid across the cortical vitreous and retina and as each of these layers offers some flow resistance the cortical vitreous will tend to be held against the inner limiting membrane of the retina while the retina will be held in apposition with the apical surface of the RPE. The importance of the dynamic apposition of the retina to its bed is illustrated by the immediate reduction in retinal adhesion which occurs at death. ${ }^{75}$

We have of course known from the time of Gonin $^{76}$ that retinal integrity is of prime importance in preventing retinal detachment and that a retinal hole is the single most important aetiological factor in the development of rhegmatogenous detachment. We know however from experimental ${ }^{77-79}$ and clinical evidence that a retinal hole alone will not necessarily lead to retinal detachment and it appears necessary that additional factors should act. In the experimental animal a retinal hole in the presence of an intact vitreous never gives rise to retinal detachment, and tamponade of open retinal breaks by formed vitreous has been suggested as one mechanism preventing retinal detachment in these circumstances. ${ }^{80-83}$ To induce experimental detachment in the animal eye a retinal hole has to be accompanied by destruction of cortical vitreous and even then the retina will often not detach unless the edges of the retinal hole are lifted or fluid is injected into the subretinal space through the retina..$^{79,84-86}$

To detach a retina experimentally appears to require not only defeat of the forces maintaining retinal adhesion but in addition the operation of forces actively tending to detach

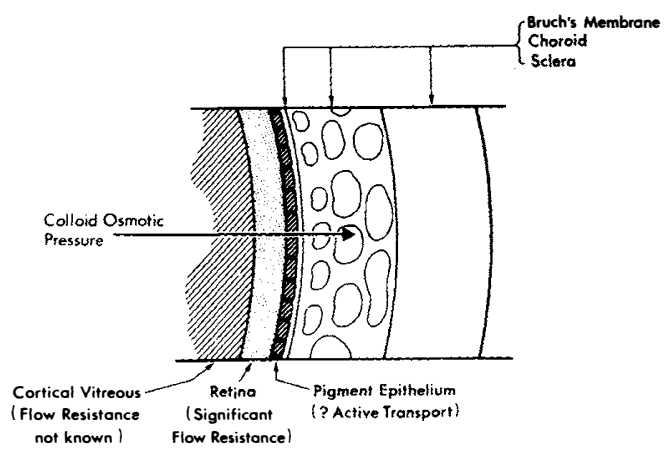

Fig. 10. Diagram to illustrate how continuous emptying of the subretinal space across the pigment epithelium maintains cortical vitreous in contact with the retina and the retina in contact with the pigment epithelium.

the retina. Traction on the retina and intraocular fluid currents are factors recently highlighted by Machemer in his Jacksonian address $^{87}$ as important in this regard.

When short term traction is applied to the intact retina any immediate separation of the

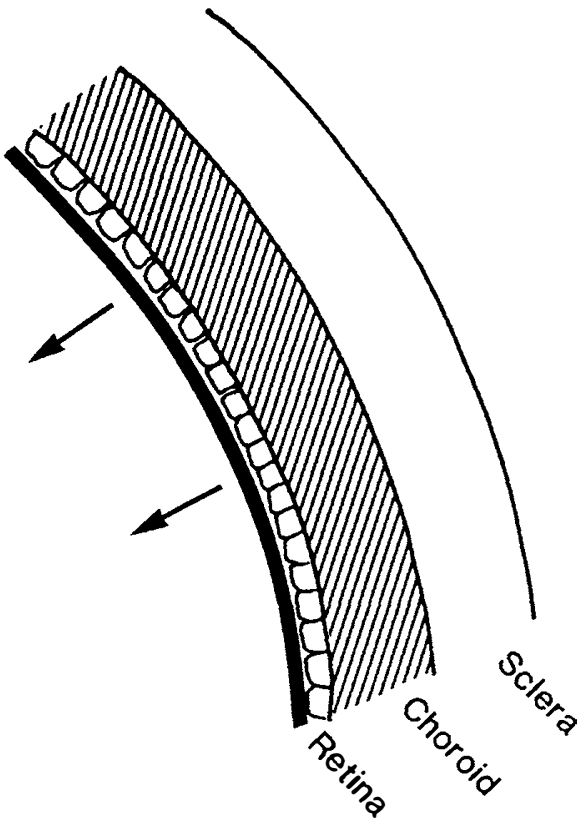

\section{SHORT TERM STRESS ON RETINA}

$$
\begin{aligned}
& \text { Sub-retinal 'vacuum' } \\
& \text { prevents detachment }
\end{aligned}
$$

Fig. 11. Diagram to illustrate transient traction on the retina. Detachment of the retina is resisted by the tendency to form a subretinal 'vacuum'. 
retina from the pigment epithelium would tend to create a vacuum and so be prevented (Fig. 11). The situation however would be different if the traction were long term for as the retina is permeable to water any tendency to form a subretinal vacuum under these conditions would be prevented by trans-retinal recruitment of water to the subretinal space (Fig. 12). Long term traction on the retina is always accompanied by leakage of fluorescein at the site of traction (Fig. 13) but whether this represents abnormal permeability of retinal vessels at this point or a breakdown of the underlying pigment epithelial barrier is not always clear. The former explanation appears to be the more likely.

Where there is a through and through break in the retina the situation is quite different. A retinal hole will allow a local increase in the

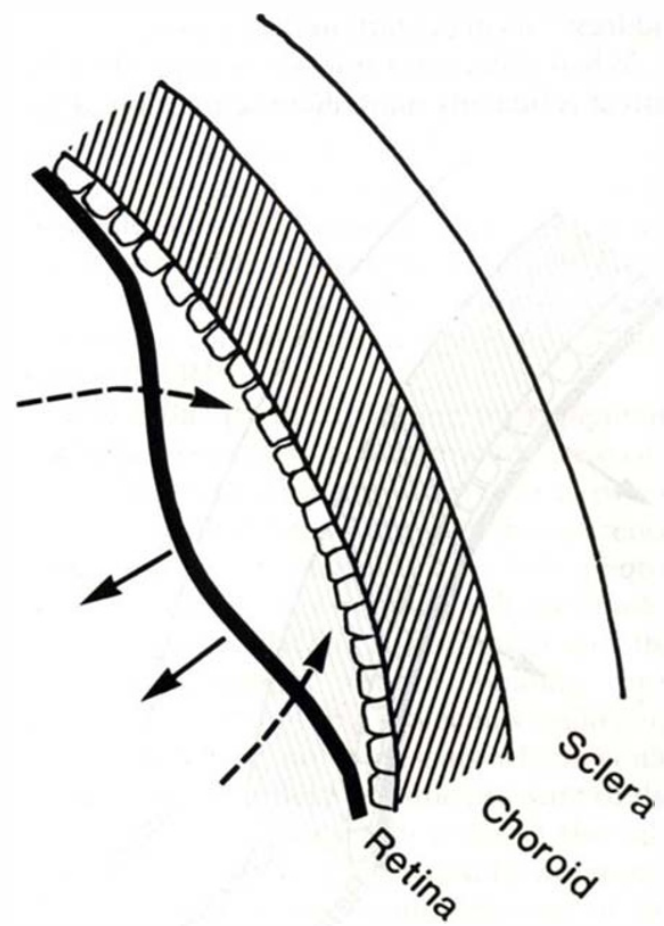

\section{LONG TERM STRESS ON RETINA}

\section{Fluid thro retina} prevents sub-retinal 'vacuum'

Fig. 12. Diagram to illustrate effects of prolonged retinal traction. Trans-retinal water movement prevents formation of a subretinal 'vacuum' and allows retinal detachment.

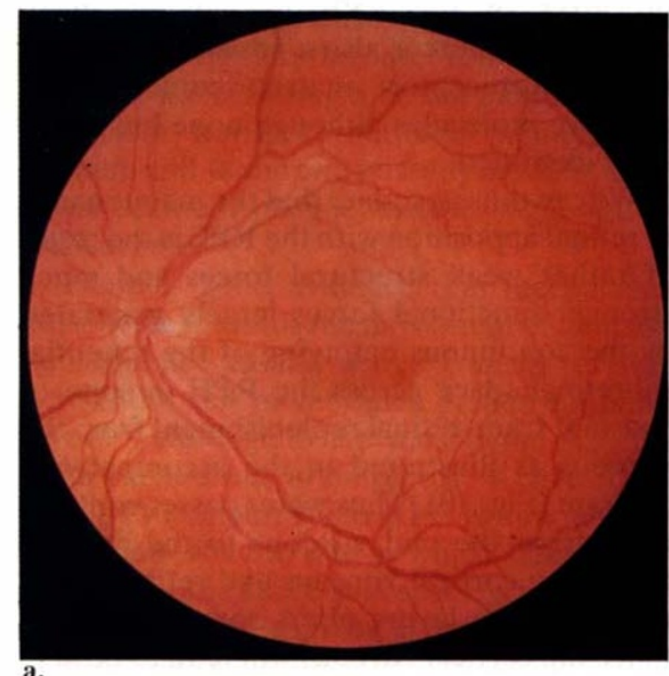

a.

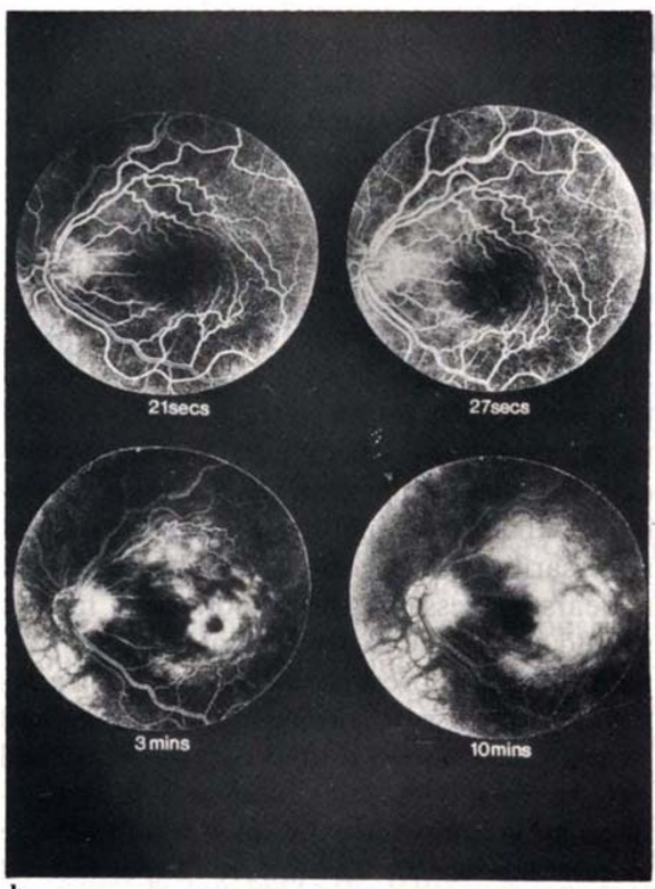

b.

Fig. 13. Fundus photograph and fluorescein angiogram of a patient exhibiting retinal traction from a preretinal membrane. The angiogram shows characteristic increased permeability of vessels at the site of the retinal traction.

rate of trans-retinal movement of water from vitreous to choroid (Fig. 14) ${ }^{88}$ but in the absence of traction will not lead to retinal detachment if the other factors aiding retinal 


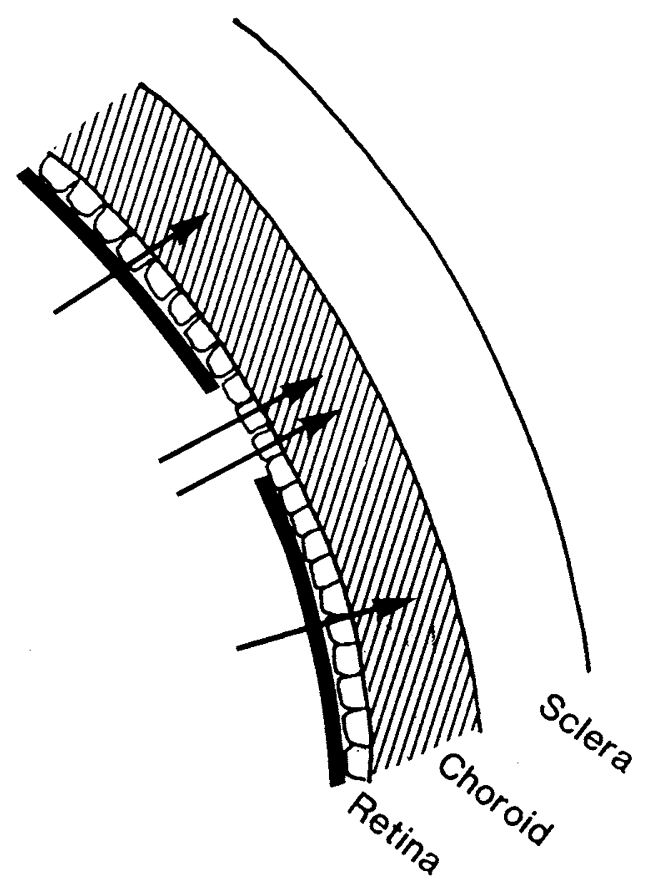

FLAT RETINAL HOLE

Fluid goes thro hole and thro retina

Fig. 14. Diagram to illustrate the effects on fluid movement of a through and through retinal break. Trans-retinal water will continue to reach the RPE through intact retina but a greatly increased movement of fluid will take place through the retinal break. In the absence of retinal traction retinal detachment may not result.

apposition are acting normally. Where traction is operating in addition to a retinal break and the two are often causally related, detachment of the retina will be unopposed by hydrostatic forces for recruitment of fluid into the subretinal space will occur with minimal resistance through the retinal hole and additionally through the surrounding intact retina (Fig. 15).

To defeat the forces maintaining retinal apposition it appears necessary that the edges of the retinal hole should be lifted and that fluid currents from the vitreous cavity should have access to the subretinal space so that the retina can be peeled off as suggested some 50 years ago by Lindner. ${ }^{86} \mathrm{He}$ coated the inside of a flask with a collodion film and tried to detach it from the wall of the flask by agitating

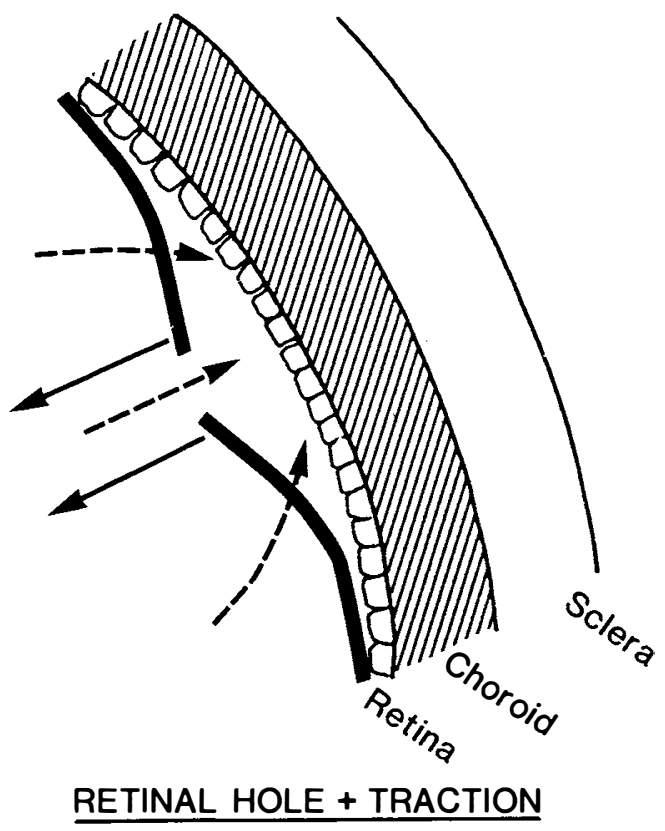

Fluid goes thro hole and retina

Fig. 15. Diagram to illustrate the effects of a through and through retinal break in the presence of retinal traction. Detachment of the retina will be unopposed by hydrostatic forces, recruitment of fluid into the subretinal space occurring with minimal resistance through the retinal hole and additionally through the surrounding intact retina.

or rotating water within the flask. He found that it was necessary that there should be a break in the collodion and that the edge of the break should be lifted to allow a current of fluid from the flask to pass under the film to strip it off (Fig. 16). The importance of this mechanism has recently been stressed by Machemer ${ }^{87}$ In the eye such a process once started will be progressive (Fig. 17). The vitreous body has viscoelastic properties resisting deformation and demonstrates elastic recoil. ${ }^{90}$ When there is a posterior detachment of the vitreous free surface effects will be present so that large movements of fluid in the vitreous cavity will be generated by eye movements. In the presence of a retinal hole especially if accompanied by vitreous traction these may precipitate a retinal detachment. An important role of the viscoelastic properties of the vitreous would be to eliminate these free surface effects. 


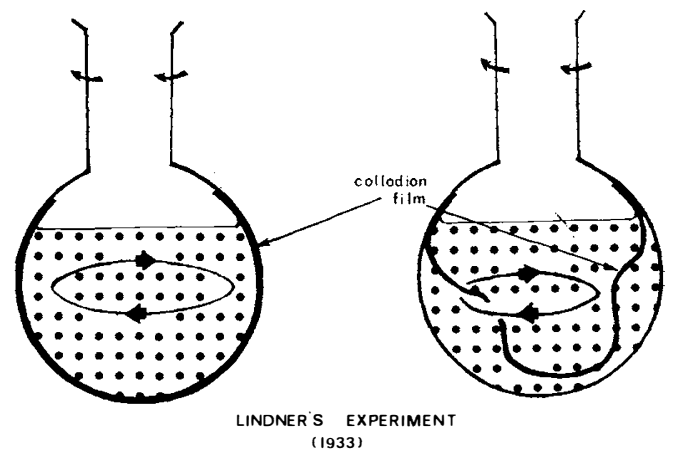

Fig. 16. Diagram to illustrate Lindner's experiments of 1937. A flask is coated internally with a film of collodion. Agitation of fluid within the flask fails to detach the collodion film unless there is a break in the film and the edges of the break are elevated.

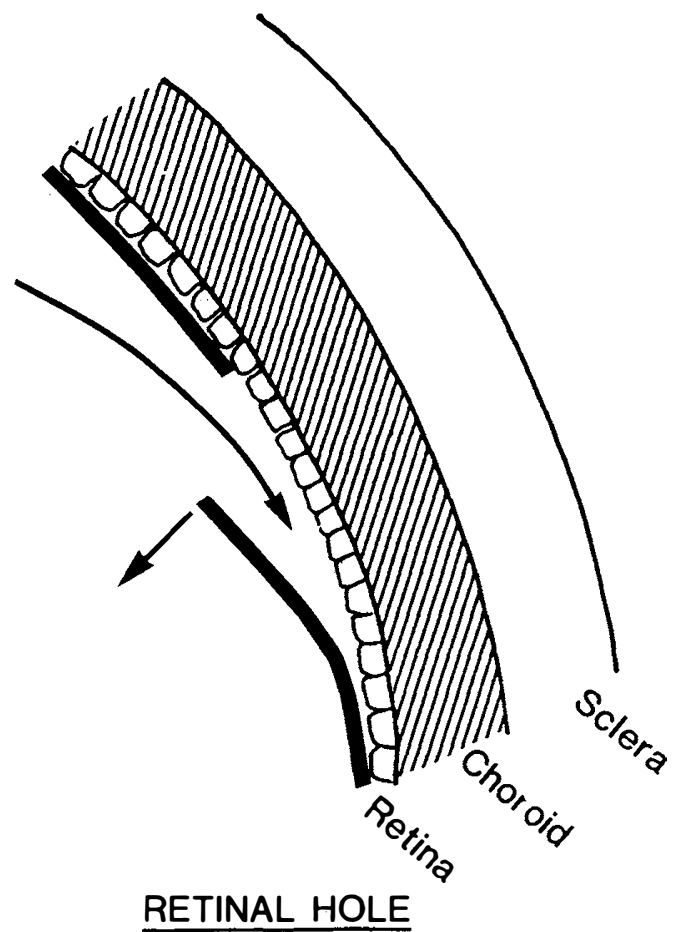

\section{Traction + lateral shearing causes detachment}

Fig. 17. Diagram to illustrate progressive detachment of the retina in the presence of a retinal break, retinal traction and retro-vitreal fluid currents.

Lifting of the edge of a retinal hole in the upper fundus may as easily be a consequence of gravity as of active traction (Fig. 18) so that holes in the upper retina are always more prone to lead to retinal detachment than are holes in the lower retina.

Thus even where there is a retinal hole formed cortical vitreous may prevent retinal detachment by tamponading the hole, preventing a flow of fluid through it to the subretinal space and by eliminating free surface effects preventing bulk lateral movements of intraocular fluid which might elevate the edges of the hole so aiding separation of the retina from its bed.

Even without formed vitreous to tamponade a retinal hole a through and through break in the absence of traction to lift the edges of the hole may not lead to the development of retinal detachment. An illustrative case is that of a young man who developed a pre-retinal traction membrane following an ocular injury (Fig. 19a). Vitrectomy and membrane peeling improved acuity from less than $6 / 60$ to $6 / 12$ but revealed the presence of a through and through flat retinal break which may possibly have been iatrogenic (Fig. 19b). The membrane peeling had been preceded by a vitrectomy, but in the absence of vitreous

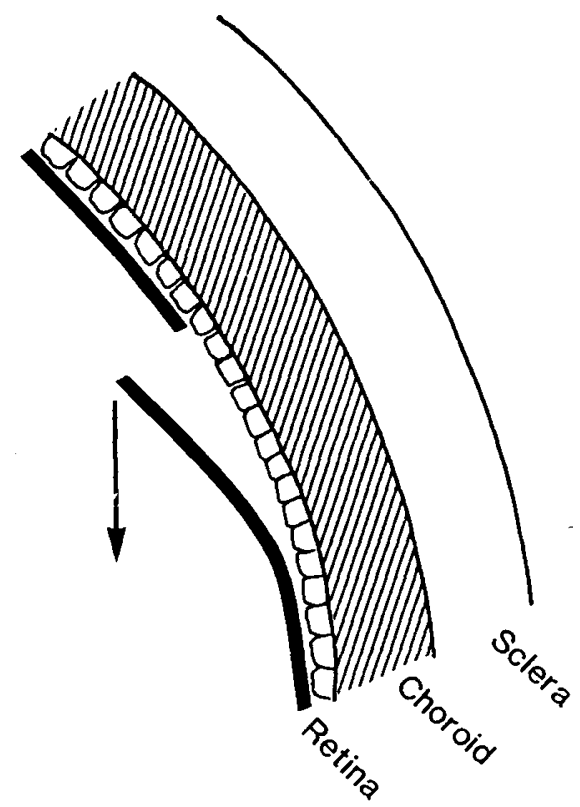

RETINAL TRACTION INCLUDES GRAVITY

Fig. 18. Diagram to illustrate effects of a retinal break in the upper fundus. Gravity will tend to lift the retina from its bed and may initiate the process of retinal detachment. 

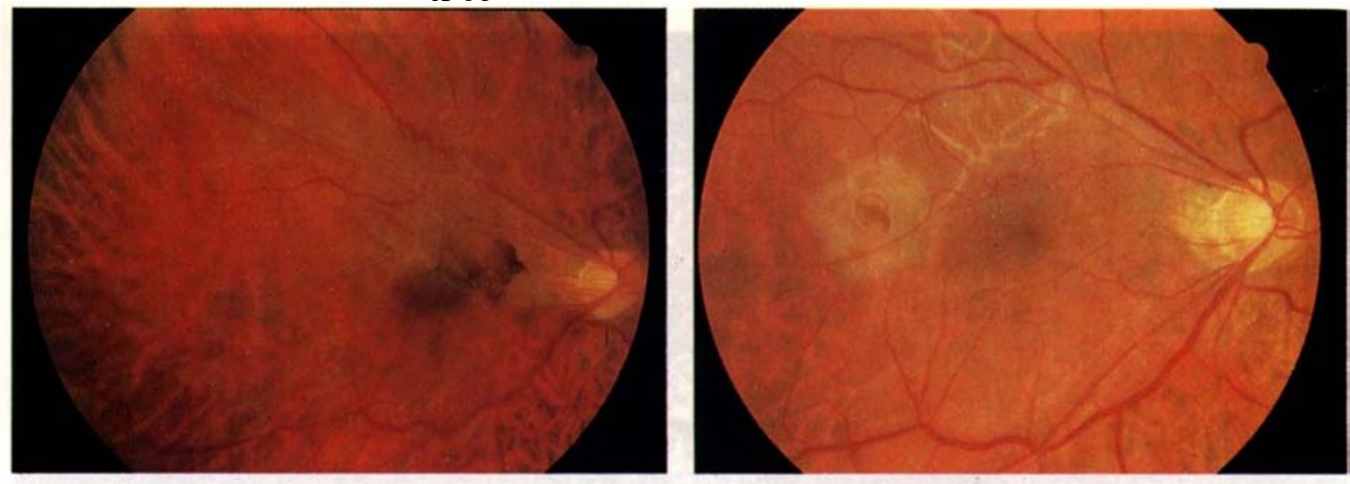

a.
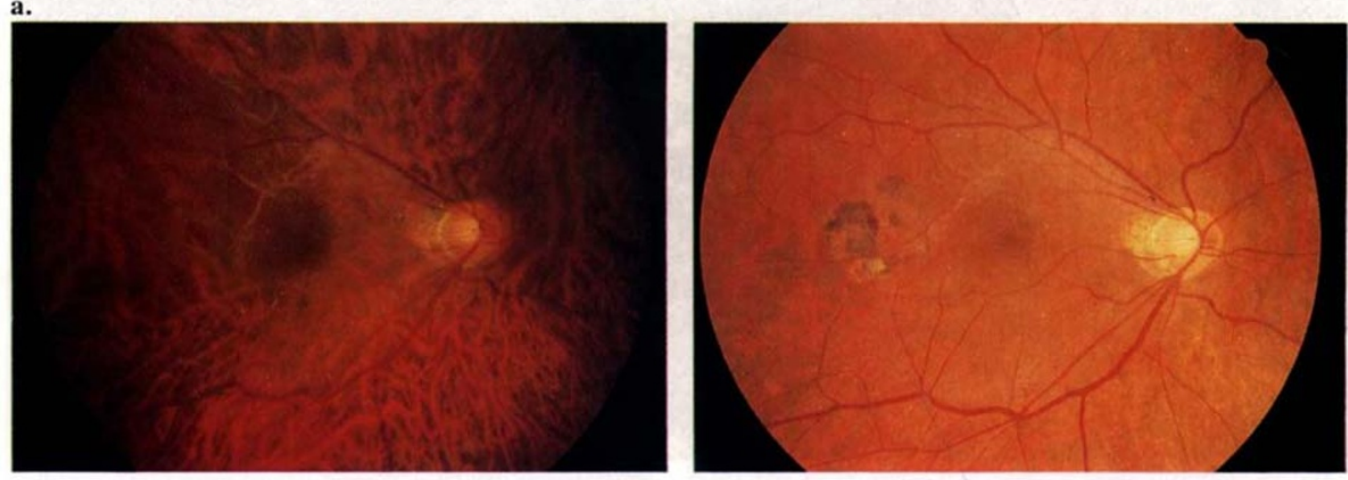

b.

Fig. 19. (a) Pre-operate appearance of an eye with a pre-retinal membrane and retinal traction following a penetrating ocular injury. Vision was reduced to less than $6 / 60$.

(b) Appearance of the fundus after vitrectomy and membrane peeling. Vision has improved to $6 / 12$ but there is a through and through retinal break temporal to the fovea.

traction the retina did not detach over an observation period of some two months although eventually to avoid the need for repeated follow up Argon laser treatment was applied round the hole (Fig. 20a).

Somewhat to our surprise in a later follow-up photograph (Fig. 20b) additional unlasered retinal holes were noted which had been present previously.

It is our experience that where a retinal break occurs during local surgical resection of a choroidal melanoma retinal detachments tend not to occur from this cause provided that no traction on the edges of the retinal break develops. ${ }^{91}$

\section{Retinal Detachment}

What happens when a retina detaches? Almost immediately the receptor outer seg-

Fig. 20. (a) In spite of theoretical reasons for believing that the risks of retinal detachment were small in this eye the hole was eventually surrounded by Argon laser burns.

(b) Other retınal holes (arrowed) were later noted but did not lead to retinal detachment.

ments left embedded in the RPE are removed by phagocytosis and the remaining outer segments on the detached retina swell up and disappear removing any possibility of a mechanical link between the RPE and the retina (Fig. 21) ${ }^{92,93}$ Great changes occur in the RPE. The RPE cells become swollen and mobile almost certainly contributing to the cells involved in pre and subretinal fibrosis. ${ }^{94.95}$ The morphology of the RPE changes dramatically with an increased polymorphism in the RPE cells, and a reduction in the proportion of hexagonal cells present (Fig. 22). In a small study (Table I) the number of RPE cells with $4,5,6,7$, or 8 slides was counted in an eye shortly after the production of an experimental detachment and in a comparable eye which had had an experimental retinal detachment for three weeks. As can be seen the eye with the longer standing retinal 


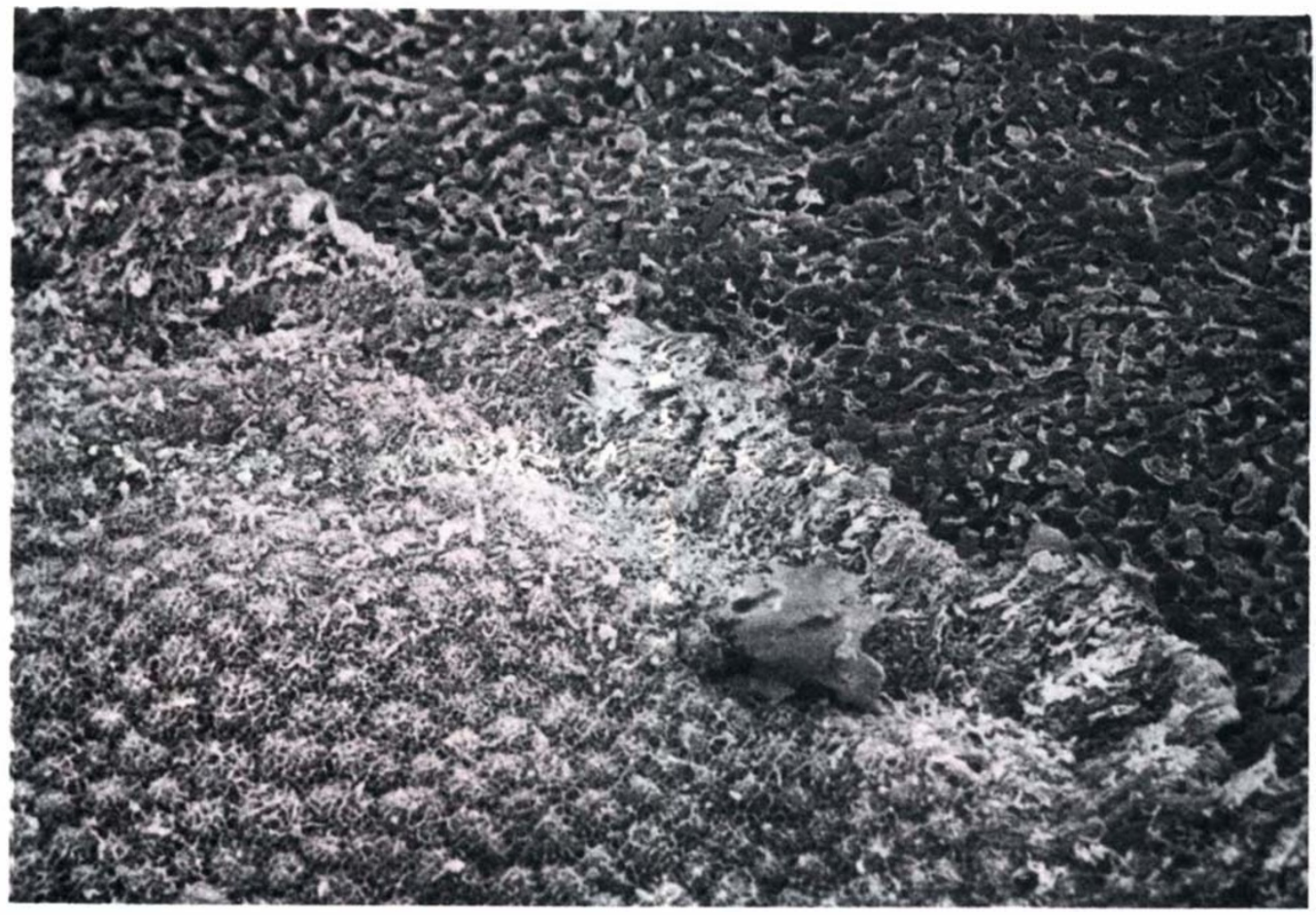

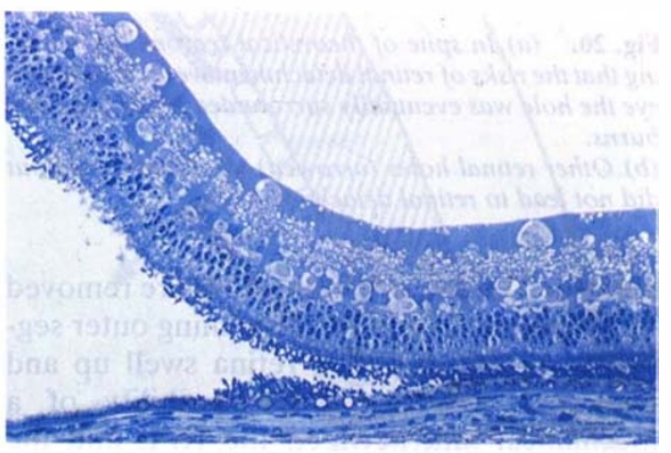

Fig. 21. (a) Scanning EM of RPE under a partial experimental retinal detachment of 4 hours' duration. In the previously non detached area (above) receptor cell outer segments (ROS) remain embedded in the $R P E$. In the detached area (below) all of the ROS have been removed by phagocytosis which is incomplete at the junction between detached and attached retina.

(b) Light micrographs of the same eye. In the detached retina the ROS have rounded up or disappeared. (a) $(\times 500)(b)(\times 150)$. (Preparation of N. McKechnie.)

detachment showed a marked decrease in the number of cells with 6 or more sides and a corresponding increase in the number of smaller cells.

Simultaneously subretinal fluid gradually changes from an aqueous-like fluid with a low
Table I Morphology of RPE in experimental retinal detachment.

\begin{tabular}{lcc}
\hline & \multicolumn{2}{c}{ Duration of detachment } \\
\cline { 2 - 3 } Type of cell & $\begin{array}{c}4 \text { hours } \\
\text { No. of cells }\end{array}$ & $\begin{array}{c}\text { 3 weeks } \\
\text { No. of cells }\end{array}$ \\
\hline Quadrilateral & $0(0 \%)$ & $34(23 \%)$ \\
Pentagonal & $33(27.5 \%)$ & $60(41 \%)$ \\
Hexagonal & $63(52.5 \%)$ & $37(25 \%)$ \\
7-sided & $21(17.5 \%)$ & $15(11 \%)$ \\
8-sided & $3(2.5 \%)$ & $0(0 \%)$ \\
\hline Total & 120 & 146 \\
\hline
\end{tabular}

protein content to a plasma-like fluid containing a lot of protein. ${ }^{86,96-99}$ In other words there is a breakdown in the posterior blood ocular barrier and consequently a loss of the osmotic forces necessary to maintain retinal apposition. It is tempting to postulate that the breakdown in the RPE barrier correlates with the obvious morphological changes which occur in the RPE cell layer. It may even be that it is a sick RPE that makes the surgical success rate in longstanding retinal detachment much lower than in recent cases. 

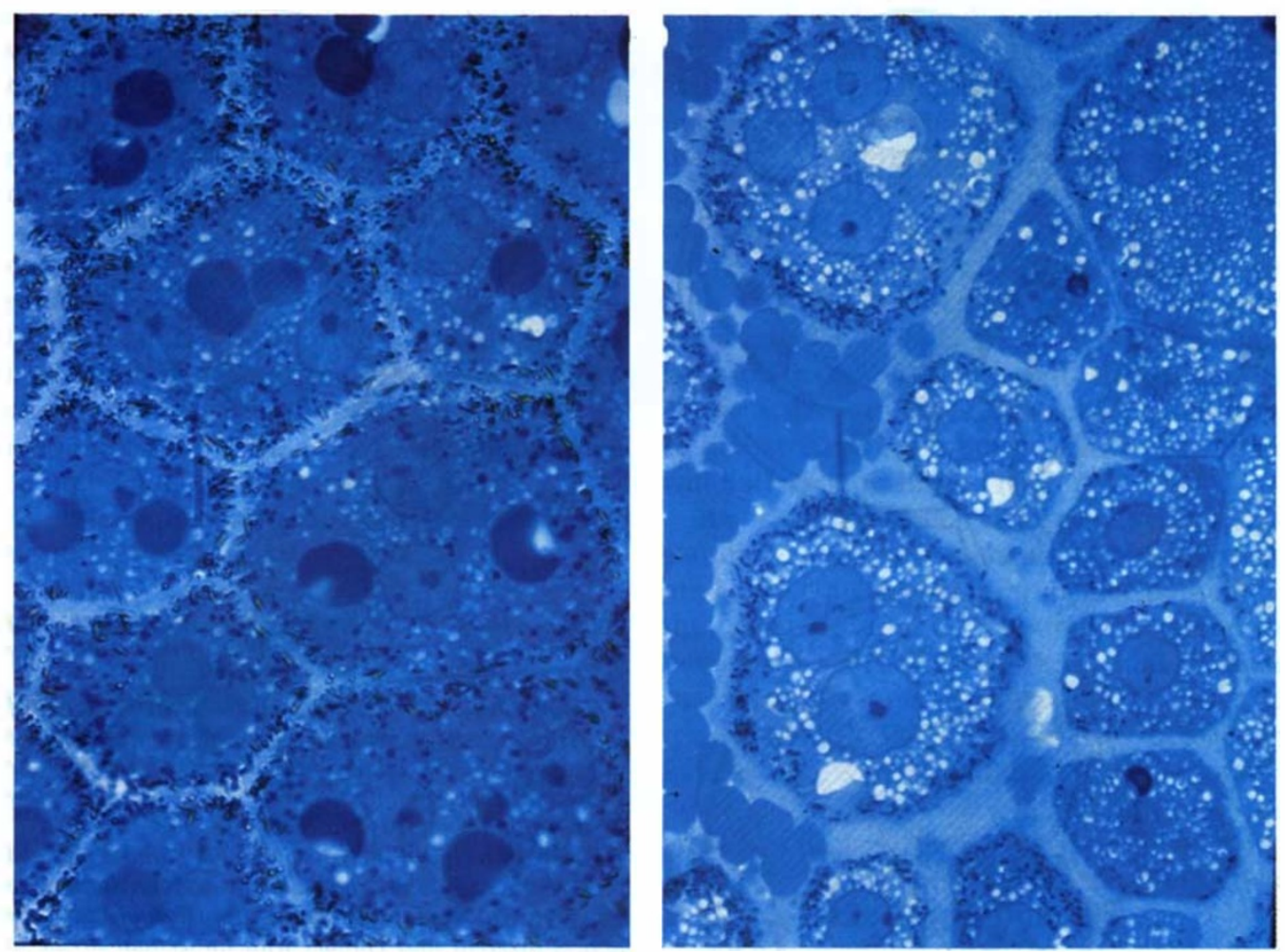

Fig. 22. Light micrographs of flat preparations of (a) normal rabbit RPE and (b) after an experimental retinal detachment of 3 weeks duration. After retinal detachment the RPE undergoes extensive polymorphism losing its hexagonal pattern. Many of the cells are smaller than normal (Toluidine blue $\times 1,000)$. (Preparations of $N$. McKechnie).

In longstanding experimental retinal detachments the azide induced increase in the standing potential of the eye ${ }^{100}$ is eventually lost ${ }^{92}$ indicating a loss of the trans-membrane movement of ions induced by this substance and suggesting a severe reduction in the transport function of the retinal pigment epithelium.

\section{Simple and Complex Retinal Detachments}

How can we apply what I have been saying to the management of retinal detachment? Rhegmatogenous retinal detachments to my mind can be conveniently divided into simple retinal detachments where the cortical vitreous gel although detached is still intact and complex retinal detachments where the vitreous structure is significantly deranged and no longer capable of internal tamponade of retinal breaks.

\section{Simple Retinal Detachment}

I have always believed that in simple retinal detachments volume reducing operations are effective largely because they result in a re-distribution of formed vitreous within the globe. A posterior detachment of the vitreous takes the cortical vitreous away from the equatorial and post-equatorial retinal surface and volume reducing operations by reducing the total volume of the globe while not affecting the volume of the residual vitreous will tend to force the residual vitreous back into contact with the anterior and even the equatorial retina allowing cortical vitreous once again to tamponade retinal holes so reducing the rate of recruitment of subretinal fluid from the vitreous cavity ${ }^{83}$ (Fig. 23). Fluid will still reach the subretinal space through intact retina but not in any greater amount than in the normal eye and the pigment epithelial pump 


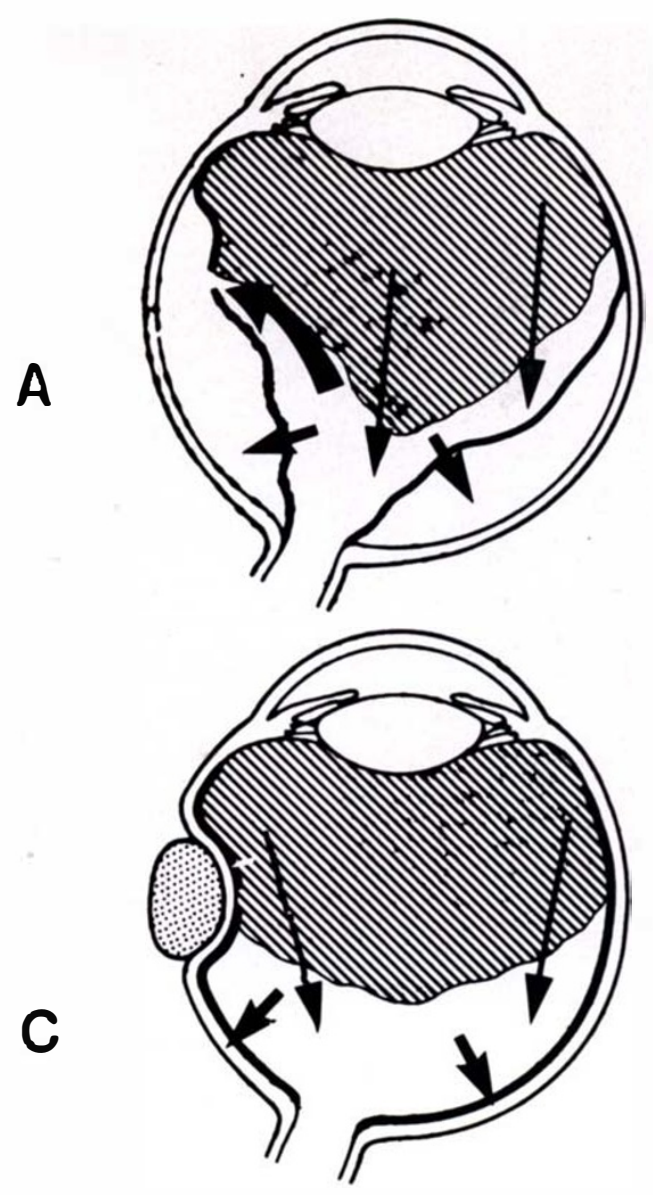

seems capable of dealing with this source of fluid provided recruitment of fluid through the retinal hole is sufficiently reduced. I believe that tamponade of the retinal hole by formed vitreous is the reason why the retina may go flat even when a retinal hole is not in contact with the buckle at the end of a volume reducing operation. On occasion part of the subretinal fluid may be loculated and slow to absorb. The rate of absorption of subretinal fluid after the hole has been successfully closed is probably determined by the integrity of the pigment epithelial 'pump' and the rate of recruitment of water from the vitreous to the subretinal space through the intact retina.

Tamponade of a retinal hole by formed vitreous will also protect the hole from lateral shearing movements of retrovitreal fluid which might tend to cause re-detachment. In simple retinal detachments the depth of the

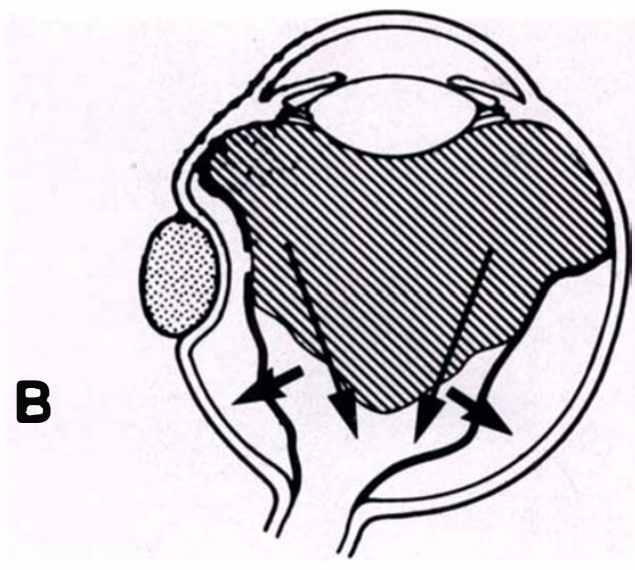

Fig. 23. Diagram to illustrate how volume reducing operations may result in tamponade of retinal holes by formed cortical vitreous.

Pre-operatively (a) there is a posterior detachment of the vitreous. Retro vitreal fluid diffusing across the vitreous from the ciliary body (arrows) reaches the subretinal space mainly through retinal breaks (heavy arrow) but also across intact retina (solid arrows).

Post-operatively (b) the volume of the globe is reduced but the volume of the detached vitreous is unchanged so that it now occupies a greater proportion of the globe and is brought into contact with the retinal break so tamponading it. Fluid from the ciliary body still reaches the residual retro vitreal space from whence it passes through the retina at a rate which is lower than the absorbing capacity of the RPE 'pump' so that the retina flattens (c).

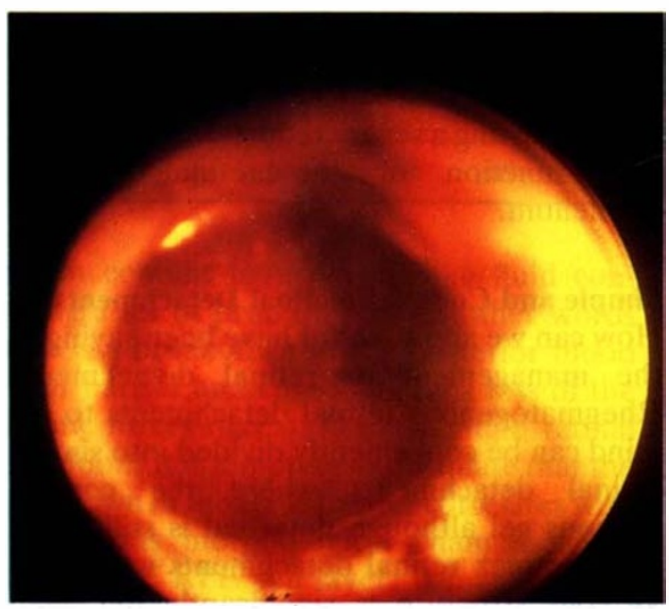

Fig. 24. In very myopic eyes with a large volume and a shrunken vitreous a very deep indent may be required to bring the vitreous into contact with the retina. 
indent required to tamponade a retinal hole will be determined by the volume of the residual vitreous relative to the intraocular volume and by the position of the retinal hole or holes. In some highly myopic eyes a very deep indent may be necessary (Fig. 24).

We know that regeneration of receptor cell outer segments occurs fairly quickly when the retina is reposed ${ }^{101}$ thus allowing the re-establishment of mechanical adhesion between retina and RPE. The question of whether a chorio-retinal scar is required to close the hole is still not fully resolved. ${ }^{102,103}$ In experimental retinal detachments closure of the hole after retinal re-apposition can occur from proliferation of RPE alone. ${ }^{86}$

\section{Complex retinal detachment}

What about complex retinal detachments? The main features of such detachments are the presence of proliferative vitreo-retinopathy with gross abnormality of the vitreous structure and the existence of vitreo-retinal traction. Many cases have had multiple surgery and there is often a gross breakdown in the posterior blood ocular barrier characterised by the presence of a highly proteinaceous subretinal fluid. The management of such detachments virtually demands vitreous surgery with the division of vitreous bands and of pre or subretinal fibrous proliferation. Additionally volume reduction is often required to relieve traction externally. Vitreous surgery and volume reduction in such eyes may very well relieve retinal traction but obviously in the absence of formed vitreous, tamponade of retinal holes cannot be by residual cortical vitreous. In the absence of cortical vitreous, tamponade of retinal holes must be achieved by a vitreous substitute.

\section{Vitreous Substitutes}

Ideally a vitreous substitute used for internal tamponade should have a surface tension ${ }^{104}$ high enough to prevent it from passing easily through a retinal break and additionally be immiscible with water. Too high a surface tension will tend to cause the injectate to break up into separate bubbles which would be optically disadvantageous. Air which has a long history in retinal detachment surgery ${ }^{105}$ and gases such as $\mathrm{SF}^{106}$ appear to have an appropriate surface tension and are well tolerated in the eye. Undoubtedly they act mainly by preventing the passage of retrovitreal fluid through the retinal hole to the subretinal space. Although per-operative pneumatic replacement of the retina has advantages in demonstrating areas of residual traction, to cure a retinal detachment a gas bubble only requires to be large enough to close the hole, for provided the pigment epithelial 'pump' is acting across a relatively intact RPE the subretinal space will be emptied and the retina will flatten on to its bed (Fig. 25).

As has already been stressed, in very longstanding retinal detachments or those associated with considerable intraocular pathology the pigment epithelial 'pump' appears to become progressively defective and in such cases it may happen that in spite of closure of retinal holes subretinal fluid may persist or indeed the retina may remain totally detached. In such eyes silicone oil, first suggested by $\mathrm{Cibis}^{107}$ and actively promulgated by Scott ${ }^{108-110}$ appears to be much more effective than other vitreous substitutes. ${ }^{111}$

What advantages does silicone oil offer over gas? Firstly of course the oil is not absorbed and retains its volume indefinitely. Oddly enough its surface tension as measured by its contact angle with a wet surface is quite low and it is certainly no better at tamponad-

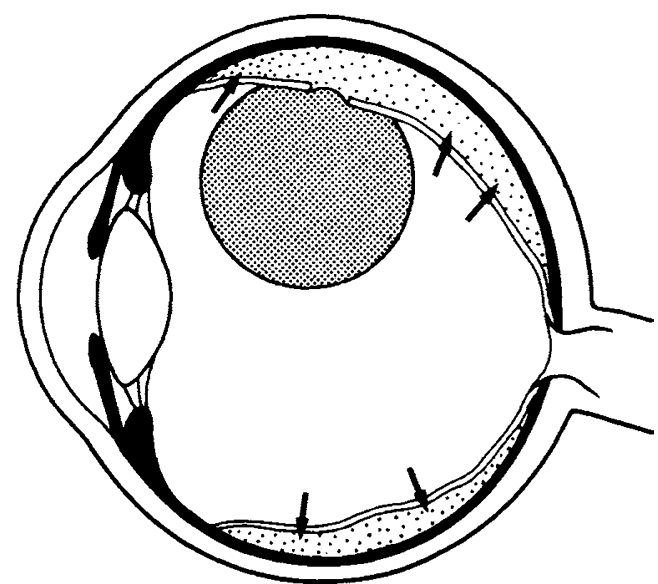

Fig. 25. Diagram to illustrate the tamponade of an upper retinal break by an intravitreal gas bubble. The bubble merely needs to be large enough to close the hole provided the pigment epithelial 'pump' is capable of emptying the subretinal space (see text). 
ing retinal holes than air or gas. Why then should it be more effective as a treatment of difficult retinal. detachments? Silicone oil competes with water to wet surfaces and I believe an important feature of silicone oil in retinal detachment surgery is its ability to waterproof the retina in addition to tamponading the retinal hole.

Silicone oil is really only effective if an almost total fill of the eye is obtained and as the oil is light and tends to float upwards a deep inferior buckle is used to improve the fill. A large quantity of oil will not only close an upper retinal hole but will remain in contact with a large area of the upper retina and prevent the passage through it of fluid that would have been destined for the subretinal space. An inferior buckle will also help to loculate fluid lying between the oil and the retina and prevent recruitment of fluid into the posterior compartment of the eye from the ciliary body (Fig. 26). The resulting reduction of fluid movement to the subretinal space through intact retina as well as through the retinal hole will undoubtedly reduce the load on the damaged pigment epithelial pump and may perhaps allow it to recover. In the presence of oil preventing trans-retinal water movement through that part of the retina with which it is

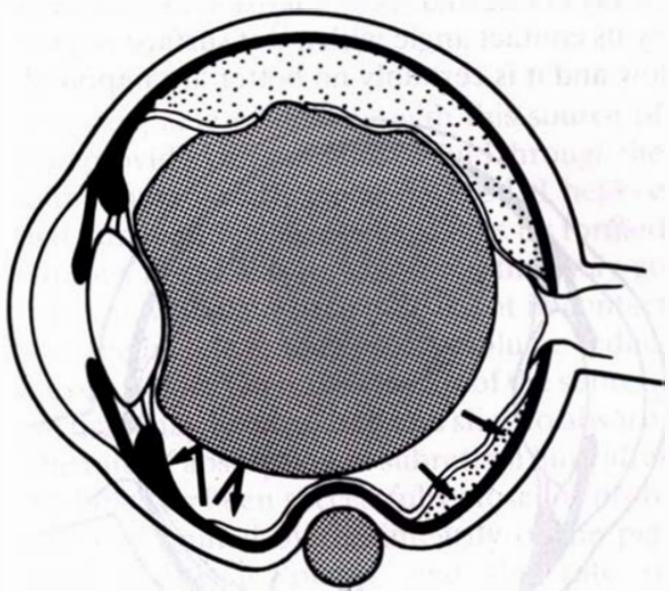

Fig. 26. Diagram to illustrate the mode of action of intraocular silicone oil in the treatment of complex retinal detachment where the pigment epithelial 'pump' is presumed to be defective. Silicone oil not only tamponades the retinal hole but reduces trans-retinal fluid movement so relieving the pigment epithelial 'pump' of much of the work involved in emptying the subretinal space. in contact the 'pump' may well be able to cope with the reduced amount of trans-retinal fluid reaching the subretinal space and under these circumstances may be capable of emptying the space and restoring the retina to its correct position.

The bigger the oil bubble and the greater the area of contact between oil and retina the greater this effect will be and where there is a complete fill the pigment epithelial 'pump' may have to deal only with the residual fluid in the subretinal space and not a constantly replenished reservoir. One might easily imagine that retinal apposition under these circumstances might allow the recovery of a sick RPE and the restoration of the blood ocular barrier so that subsequently the oil could be removed and the restored epithelial 'pump' given the task of keeping the retina flat. As we know not all eyes can tolerate removal of the oil with impunity for removal of the oil may be followed by recurrence of the retinal detachment and it may be that in some cases recovery of the pigment epithelial 'pump' is incomplete.

Have we any evidence to support these speculations? In the experimental animal if a vitrectomy is carried out and half the vitreous cavity replaced by silicone oil (Fig. 27) measurement of the rate of transfer of tritiated water from the mid vitreous across the oil to the choroid shows that the rate of transfer is

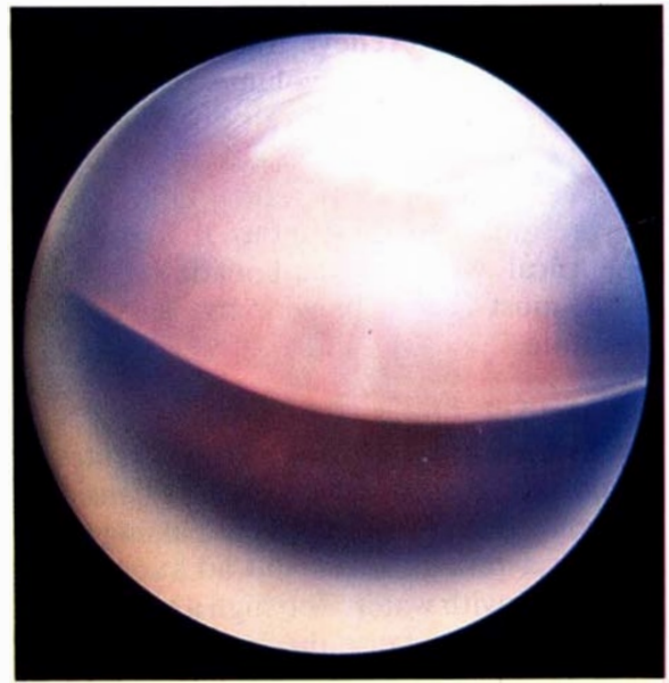

Fig. 27. Rabbit eye which has undergone complete vitrectomy and a 50 per cent replacement of the vitreous with silicone oil. 

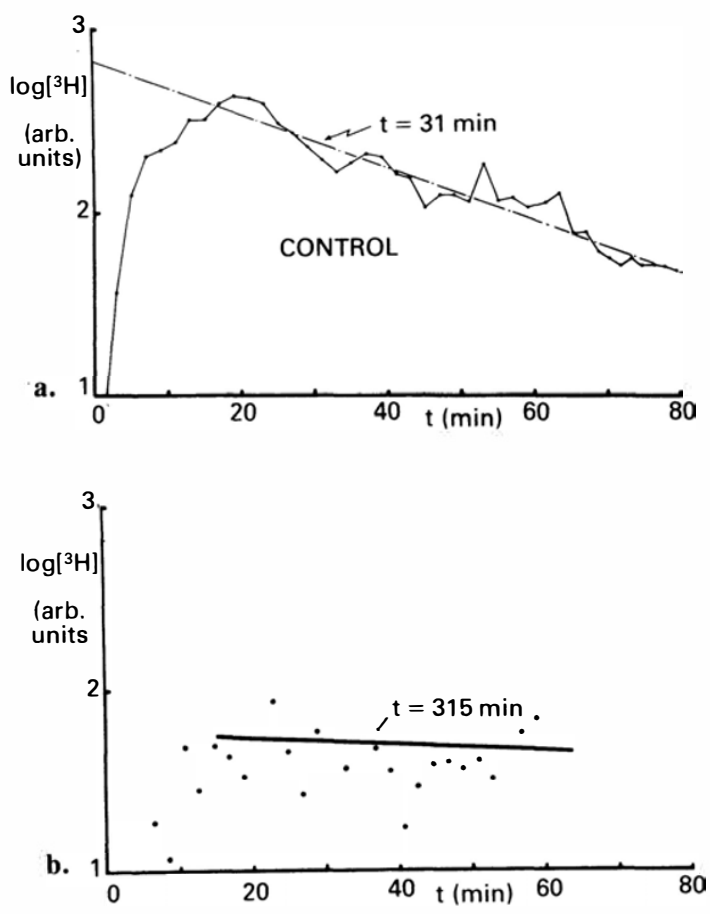

Fig. 28. Rate of appearance of intravitreally injected tritiated water in a vortex vein draining the upper choroid of the eye illustrated in Fig. 26 where half the vitreous has been replaced by silicone oil. The rate of transfer of tritiated water from the vitreous to the choroid is greatly reduced. (a) typical control animal, and (b) after 50 per cent silicone replacement of vitreous.

grossly decreased approaching zero in some experiments (Fig. 28) supporting the view that silicone oil prevents water movement through the intact retina to the choroid. Some further support for the hypothesis that waterproofing the retina is an important factor in the efficacy of silicone oil in the treatment of complex retinal detachment can be found in the gross retinal oedema which sometimes follows the removal of oil in such cases, suggesting that water is again penetrating the retina from the vitreous cavity but perhaps not being effectively removed by the RPE 'pump'.

Unfortunately as silicone oil competes with water to wet surfaces not only may it waterproof the retina it may also waterproof the back of the lens interfering with metabolic exchange and leading to cataract (Fig. 29) or waterproofing the back of the cornea if it gets
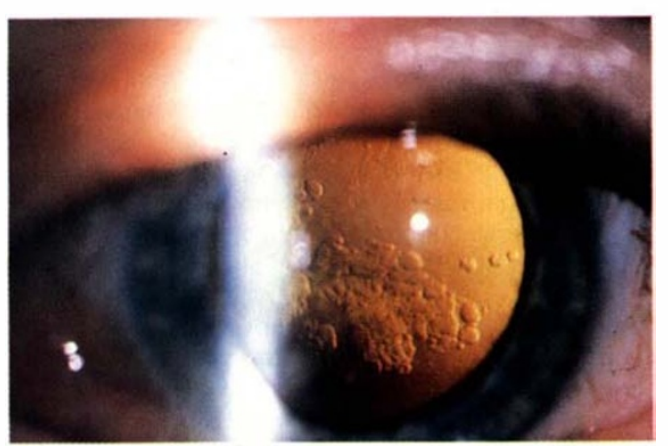

Fig. 29. Typical silicone cataract possibly due to the water proofing effect of silicone oil interfering with metabolic exchange across the posterior lens capsule.

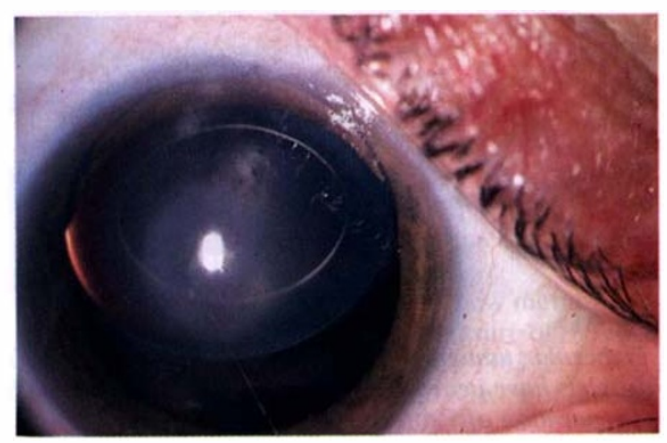

Fig. 30. Corneal endothelial decompensation in an aphakic eye successfully treated for complex retinal detachment by silicone oil replacement of the vitreous. Forward movement of the oil has led to contact with corneal endothelium and failure of the endothelial pump mechanism.

into the anterior chamber so interfering with the corneal endothelial pump leading to corneal decompensation (Fig. 30). Under some circumstances silicone oil in contact with the cornea or lens may delay the development of opacity in either structure possibly by preventing uptake of water from the aqueous or vitreous cavities. Other disadvantages of silicone oil are the occasional appearance of emulsified oil in the anterior chamber and its penetration of tissues such as the trabecular meshwork (Fig. 31). A vitreous substitute with the waterproofing characteristics of silicone but none of the disadvantages would be very useful. Perhaps this role may be filled by one of the newer fluorinated hydrocarbon gases $^{112}$ which in their higher molecular weights are very slowly absorbed from the vitreous cavity. Possibly a new polymer will 


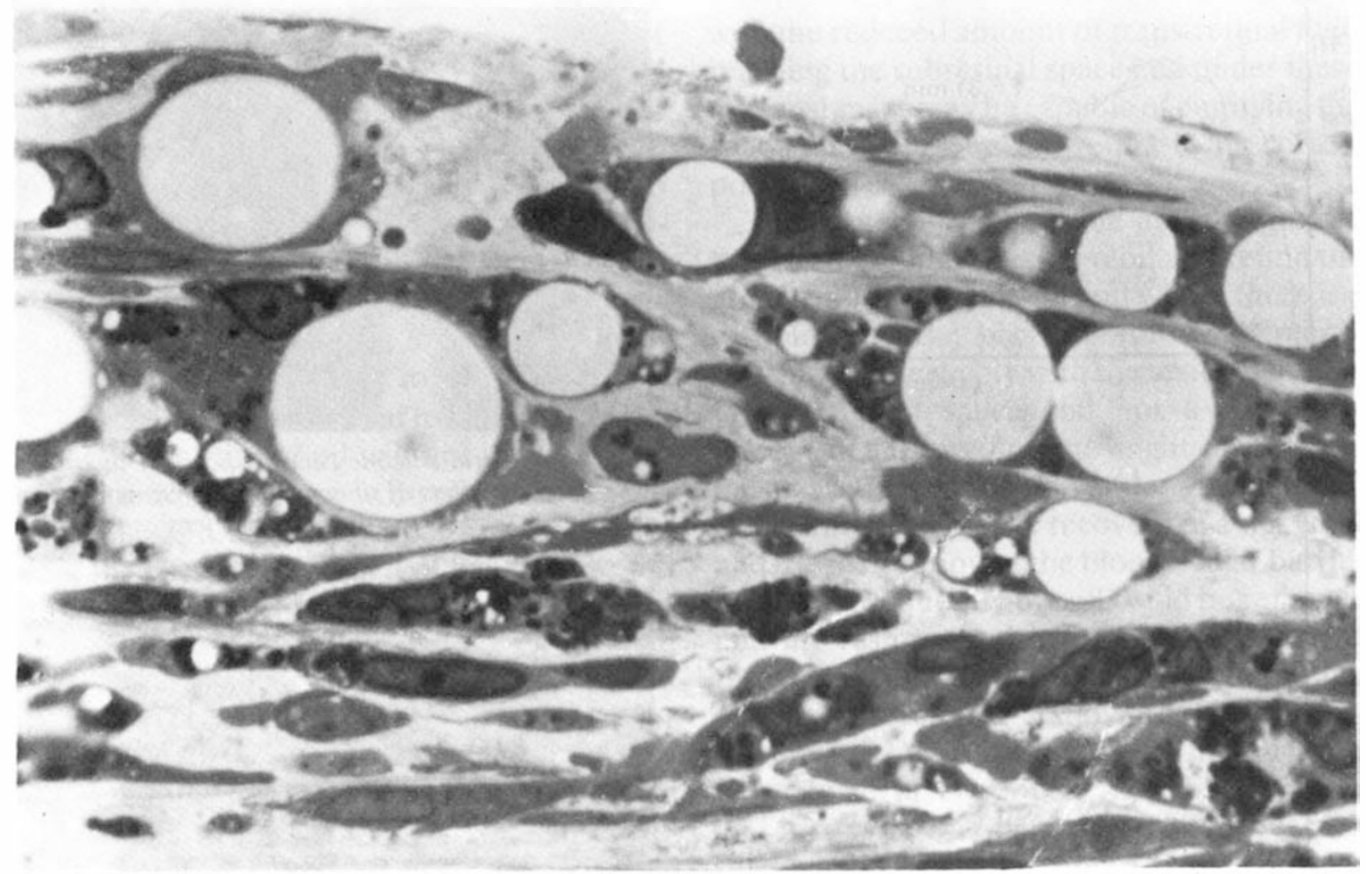

Fig. 31.

Trabecular tissue from an eye excised some years after treatment of a retinal detachment with silicone oil. Oil droplets have penetrated the trabecular tissue $(\times 1,000)$.

(Preparation of Professor W. R. Lee.)

emerge from the laboratories of the polymer chemists which will have the characteristics we seek.

Retinal detachment surgery has come a long way since Gonin. Further advances will depend not only on our technological ingenuity, but on a clearer understanding of the forces that influence retinal apposition. High on the list of matters requiring further study is a detailed investigation of the pigment epithelial 'pump' mechanism and particularly the factors that influence its recovery in complex longstanding retinal detachments. In furthering our understanding, continuing close co-operation is required between the laboratory worker and the retinal surgeon.

There are other aspects of the vitreous and other glycosaminoglycan containing compartments in the eye which need further investigation. There is evidence that some tissues with a high glycosaminoglycan content actively inhibit angiogenesis. ${ }^{113}$ The question of whether the vitreous for example acts purely as a barrier to the diffusion of angiogenic factors elaborated in the retina in conditions such as diabetic retinopathy or whether it has an active inhibitory role has still not been established. One could even postulate that the glycosaminoglycans of the inter-photoreceptor matrix might have a role in the prevention of subretinal neovascularisation. Like all other speculations these are matters which will have to be tested experimentally.

When a structural engineer builds a bridge he builds in a safety factor and depending on the economics of the situation this is often greater than is strictly required. The vitreous is one of the many safety factors built into the eye to counter certain adverse circumstances. Most of the time it is not needed but when we dispense with it we reduce the eye's ability to cope with the results of disease or injury, in particular we reduce the ability of the eye to prevent retinal detachment. We should be careful of the vitreous-it is one of our insurance policies. 
I should like to acknowledge the help of many people who over the years have contributed to the various aspects of the work which form the basis of this lecture. My thanks are due to Mrs. D. Aitken, Senior Technician, Tennent Institute for her help with experimental work, light and electronmicroscopy and to the late $\mathrm{Mr}$. Martin Bass, Senior Technician, Institute of Ophthalmology, London for his help with early work on experimental retinal detachment. Mrs. A. Currie, Senior Technician, Tennent Institute was responsible for the preparation of the illustrative material and the manuscript was typed by Mrs. J. Murray. I should like to thank Dr. D. Allan, Senior Physicist in the Tennent Institute for his continuing help with radio tracer experiments, Professor W. R. Lee and a large number of ex PhD students of the Tennent Institute-Dr. I. Grierson, London, Dr. N. McKechnie, London, Dr. N. Johnston, Cardiff, Dr. P. McMenamin, Glasgow, Dr. H. Moseley, Glasgow all of whose work has contributed to this presentation. and some of whose illustrations are reproduced here.

Part of the experimental work was supported by a grant from the British Medical Association (John Clarke Award).

Figures 25 and 26 were previously published in the Australian Journal of Ophthalmology.

\section{References}

${ }^{1}$ Foulds WS: The local excision of choroidal melanomata. Trans Ophthalmol Soc UK 1973, 93: 343-6.

2 Foulds WS: Experience of the local excision of uveal melanomas. Trans Ophthalmol Soc UK 1977, 97: 412-15.

${ }^{3}$ Foulds WS: Current options in the management of choroidal melanoma. Trans Ophthalmol Soc UK 1983, 103: 28-34.

${ }^{4}$ Balazs EA, Laurent TC, Laurent UBG, de Roche MH, Bunney DM: Studies on the structure of the vitreous body VIII. Comparative Biochemistry. Arch Biochem Biophys 1959, 81: 464-79.

${ }^{5}$ Balazs EA: Molecular morphology of the vitreous body. In: Structure of the Eye, Smelser GK (ed) New York 1961, Academic Press Inc, 293-310.

${ }^{6}$ Mathews MB: The interaction of collagen and acid mucopolysaccharides. A model for connective tissue. Biochem J 1965, 96, 710-16.

${ }^{7}$ Serafini-Fracassini A, Wells PJ, Smith JW: Studies on the interactions between glycosaminoglycans and fibrillar collagen. In: Chemistry \& Molecular Biology of the intercellular matrix. Balazs EA (ed), New York 1970, Academic Press Inc, 2 1201-5.

${ }^{8}$ Ogston AG: The biological function of the glycosaminoglycans. In: Chemistry and Molecular biology of the intercellular matrix. Balazs EA (ed), London 1970, Academic Press Inc, 123140.

${ }^{9}$ Comper WD and Laurent TC: Physiological func- tions of connective tissue polysaccharides. Physiol Review 1978, 58: 255-315.

${ }^{10}$ Zimmerman LE and Eastham AB: Acid mucopolysaccharide in the retinal pigment epithelium and visual cell layer of the developing mouse eye. Am J Ophthalmol 1959, 47: 488-98.

${ }^{11}$ Rohlich P: The interphotoreceptor matrix: electronmicroscopic and histochemical observations in the vertebrate retina. Exp Eye Res 1970, 10: 80-96.

12 Berman ER: Mucopolysaccharides (glycosaminoclycans) of the retina: identification, distribution and possible biological role. Mod Prob Ophthalmol 1969, 8: 5-31.

${ }^{13}$ Feeney L: The interphotoreceptor space: histochemistry of the matrix. Develop Biol 1973, 32: 115-28.

${ }^{14}$ Bridges $\mathrm{CD}$ and Adler AJ (eds): The interphotoreceptor matrix in health and disease. New York 1985, Alan R. Liss Inc.

${ }^{15}$ Maurice DM: In: The Eye. Davson H (ed). Vol I, New York, 1962, Academic Press Inc, 289-368.

${ }^{16}$ Maurice DM: In: The transparency of the cornea. Duke Elder WS and Perkins ES (eds), Oxford 1960, Blackwell, pp 67-71.

${ }^{17}$ Hedbys BO, Mishima S, Maurice DM: The inhibition pressure of the corneal stroma. Exp Eye Res 1963, 2: 99-111.

${ }^{18}$ Hedbys BO and Dohlman CH: A new method for determination of the swelling pressure of the corneal stroma in vitro. Exp Eye Res 1963, 2: 122-9.

${ }^{19}$ Fatt I and Hedbys BO: Flow conductivity of human corneal stroma. Exp Eye Res 1970, 10: 237-42.

${ }^{20}$ Barany EH and Scotchbrook S: Influence of testicular hyaluronidase on the resistance to flow through the angle of the anterior chamber. Acta Physiol Scand 1954, 30: 240-8.

${ }^{21}$ Barany EH: The action of different kinds of hyaluronidase on the resistance to flow through the angle of the anterior chamber. Acta Ophthalmol 1956, 34: 397-402.

${ }^{22}$ François J, Rabaey M, Neetens A: Perfusion studies on the outflow of aqueous humor in human eyes. Arch Ophthalmol 1956, 55: 193-204.

${ }^{23}$ Pedlar C: The relationship of hyaluronidase to aqueous outflow resistance. Trans Ophthalmol Soc UK 1956, 76: 51-63.

${ }^{24}$ Vrabec F: The amorphous substance in the trabecular network. Br J Ophthalmol 1957, 41: 20-4.

${ }^{25}$ Zimmerman LE: Demonstration of hyaluronidase sensitive acid mucopolysaccharides in trabecula and iris in routine paraffin sections of adult human eyes. Am J Ophthalmol 1957, 44: 1-4.

${ }^{26}$ Segawa K: Ultrastructural changes of the trabecular tissue in primary open angle glaucoma. Japn J Ophthalmol 1975, 19: 317-38.

${ }^{27}$ Grierson I, Lee WR, Abram S: The distribution and significance of hyaluronidase sensitive materials in the trabecular wall of Schlemm's canal. Trans Ophthalmol Soc UK 1977, 97: 739-45.

${ }^{28}$ Mizokami K: Demonstration of masked glycosaminoglycans in the uveal human trabecular meshwork. Jpn J Ophthaimol 1977, 21: 57-71. 
${ }^{29}$ McMenamin PG: Function and morphological studies of the primate outflow apparatus. Thesis for PhD, University of Glasgow, 1981.

${ }^{30}$ Bill $A$ and. Phillips CI: Uveoscleral drainage of aqueous humor in human eyes. Exp Eye Res 1971, 12: $275-81$.

${ }^{31}$ Bill A: Some aspects of tissue fluid dynamics in the eye. In: Vision and Circulation. Cant JS (ed), St Louis, 1976, The CV Mosby Co, 333-8.

${ }^{32}$ Moseley H, Foulds WS, Allan D, Kyle PM: Routes of clearance of radioactive water from the rabbit vitreous. Br J Ophthalmol 1984, 68: 145-51.

${ }^{33}$ Cunha-Vaz JC and Maurice DM: The active transport of fluorescein by the retinal vessels and the retina. J Physiol 1967, 191: 467-86.

${ }^{34}$ Palestine AG and Brubacker RF: Pharmakokinetics of fluorescein in the vitreous. Invest Ophthalmol Vis Sci 1981, 21: 542-9.

${ }^{35}$ Blair NP, Zeimer RC, Rusin MM, Cunha-Vaz JC: Outward transport of fluorescein from the vitreous in normal human subjects. Acta Ophthalmol 1983, 101: 1117-21.

36 Ogura Y, Tsukahara Y, Saito I, Kondo T: Estimation of the permeability of the blood retinal barrier in normal individuals. Invest Ophthalmol Vis Sci 1985, 26: 969-76.

37-Moseley H: Studies of fluid movement in the eye. PhD Thesis, University of Glasgow, 1980.

${ }^{38}$ Ogston AG and Sherman TF: Effects of hyaluronic acid upon diffusion of solutes and flow of solutes. J Physiol 1961, 156: 67-74.

${ }^{39}$ Foulds WS, Allan D, Moseley H, Kyle PM: Effect of intravitreal hyaluronidase on the clearance of tritiated water from the vitreous to choroid. $\mathrm{Br} \mathrm{J}$ Ophthalmol 1985, 69: 529-32.

${ }^{40}$ Cantrill HC and Pederson JE: Experimental retinal detachment III vitreous fluorophotometry. Arch Ophthalmol 1982, 100: 1810-13.

${ }^{41}$ Doft BS, Weiskoff J, Nillsson-Ehle I, Wingard LB: Amphotericin clearance in vitrectomised versus non-vitrectomised eyes. Ophthalmology 1985, 92: $1601-5$.

${ }^{42}$ Laurent TC, Bjork I; Pietruszkiewicz A et al.: On the interaction between polysaccharides and other macromolecules II: The transport of globular particles through hyaluronic acid solutions. Biochem Biophys Acta 1963, 78: 351-9.

${ }^{43}$ Folger H, Weiss I, Glaves D, Subjeck JR, Harlos JP: Translational movement of macrophages through media of different viscosities. J Cell Sci 1978, 31: 245-57.

${ }^{44}$ Forrester J and Williamson PC: Inhibition of leukocyte locomotion by hyaluronic acid. J Cell Sci 1981, 48: 315-31.

${ }^{45}$ Foulds WS: Aetiology of retinal detachment. Trans Ophthalmol Soc UK 1975, 95: 112-27.

${ }^{46}$ Foulds WS: Factors influencing visual recovery after retinal detachment surgery. Trans Ophthalmol Soc UK 1980, 100: 72-7.

${ }^{47}$ Moseley H: Mathematical analogue of the posterior blood ocular barriers. Trans Ophthalmol Soc UK 1977, 97: 565-8.

${ }^{48}$ Fatt I and Shantinath K: Flow conductivity of retina and its role in retinal adhesion. Exp Eye Res 1971, 12: 218-26.

${ }^{49}$ Maurice DM, Salmon J, Zauberman H: Subretinal pressure and retinal adhesion. Exp Eye Res 1971, 12: $212-17$.

${ }^{50}$ Bernstein $\mathrm{MH}$ and Hollenberg MJ: Movement of electron-opaque markers through the capillaries of the retina. In: Symposium on structure of the eye II, Rohen JW (ed), Stuttgart 1965, Schauthauer 129.

${ }^{51}$ Cohen AI: A possible cytological basis for the ' $R$ ' membrane in the vertebrate eye. Nature (Lond) 1965, 205: 1222-3.

52 Peyman GA, Spitznas M, Straatsma BR: Chorioretinal diffusion of peroxidase before and after photocoagulation. Invest Ophthalmol Vis Sci 1971, 10: 489-95.

53 Johnson NF, McNaught EI, Foulds WS: Effect of photocoagulation on the barrier function of the pigment epithelium II. A study by electronmicroscopy. Trans Ophthalmol Soc UK 1977, 97: 64051.

${ }^{54}$ Asayama K: In vivo study on the absorption of the subretinal fluid. 2. Studies on absorption of tracers injected between the sensory retina and the pigment epithelial layer. Acta Soc Ophthalmol Jpn 1976, 80: 598-607.

${ }^{55}$ Frambach DA and Marmor MF: The rate and route of fluid resorption from the subretinal space of the rabbit. Invest Ophthal Vis Sci 1982, 22: 292302.

${ }^{56}$ Marmor MF, Porteus M, Negi A, Immel J: Validation of a model of non-rhegmatogenous retinal detachment. Current Eye Res 1984, 3: 515-18.

${ }^{57}$ Negi A and Marmor MF: Effects of subretinal and systemic osmolarity on the rate of subretinal fluid absorption. Invest Ophthalmol Vis Sci 1984, 25: 616-20.

${ }^{58}$ Marmor MF, Negi A, Maurice DM: Kinetics of macromolecules injected into the subretinal space. Exp Eye Res 1985, 40: 687-96.

${ }_{59}$ Marmor MF: Retinal detachment from hyperosmotic intravitreal injection. Invest Ophthalmol Vis Sci 1979, 18: 1237-44.

${ }^{60}$ Marmor MF, Abdul-Rahim AS, Cohen DS: The effect of metabolic inhibitors on retinal adhesion and subretinal fluid absorption. Invest Ophthalmol Vis Sci 1980, 19: 893-903.

${ }^{61}$ Lai YL, Wiggert B, Liu YP, Chader GJ: Interphotoreceptor retinol binding proteins: possible transport vehicles between components, of the retina. Nature (Lond) 1982, 298: 848-9.

62 Adler A J and Klucznik KM: Proteins and glycoproteins of the bovine interphotoreceptor matrixcomposition and fractionisation. Exp Eye Res 1982, 34: 423-34.

${ }^{63}$ Lion GI, Bridges CDB, Fong SL, Alvarez RA, Gonzales-Fernandez F: Vitamin A transport between retina and pigment epithelium-an intertitial protein carrying endogenous retinol (interstitial retinol binding protein). Vision Res 1982, 22: 1457-67.

${ }^{64}$ Pfeiffer B, Wiggert B, Lee L, Zonenberg B, New- 
some D, Chader G: The presence of soluble interphotoreceptor retinol binding proteins (IRBP) in the retina interphotoreceptor space. $J$ Cell Physiol 1983, 117: 333-41.

${ }^{65}$ McKechnie NM, Keegan WA, Converse CA, Foulds WS: Glycosaminoglycans: their effect on rod outer segment phagocytosis by bovine retinal pigment epithelium explants. Invest Ophthalmol Vis Sci 1985, 26: Suppl.

${ }^{66}$ Lasansky A and de Fisch FW: Potential current and ionic fluxes across the isolated retinal pigment epithelium and choroid. J Gen Physiol 1966, 49: 913-24.

${ }^{67}$ Miller SS and Steinberg RH: Active transport of ions across frog retinal pigment epithelium. Exp Eye Res 1977, 25: 235-48.

${ }^{68}$ Miller SS, Hughes BA, Machen TE: Fluid transport across retinal pigment epithelium is inhibited by cyclic AMP. Proc Nat Acad Sci, USA 1982, 79: 2111-15.

${ }^{69}$ Frambach DA and Misfeldt DS: Furosamide sensitive $\mathrm{C} 1$ transport in embryonic chicken retinal pigment epithelium. Am J Physiol 1983, 244: 679-85.

${ }^{70}$ di Mattio J, Degnan KZ, Zadunaisky JA: A model for trans epithelial ion transport across the isolated retinal pigment epithelium of the frog. Exp Eye Res 1983, 37: 409-20.

${ }^{71}$ Hughes BA, Miller SS, Machen TE: The effects of cyclic AMP on fluid absorption and ion transport across frog retinal pigment epithelium. J Gen Physiol 1984, 83: 875-99.

72 Marmor MF and Maack T: Enhancement of retinal adhesion and subretinal fluid resorption by acetazolamide. Invest Ophthalmol Vis Sci 1982, 23: $121-4$.

${ }^{73}$ Negi A and Marmor MF: Quantitative evaluation of metabolic transport of subretinal fluid. Invest Ophthalmol Vis Sci 1986, 27: 1564-8.

${ }^{74}$ Lucci MS and Warnock DG: Effects of anion transport inhibitors on $\mathrm{NaCl}$ reabsorption from rat superficial proximal convoluted tubule. J Clin Invest 1979, 64: 570-99.

${ }^{75}$ Zauberman H, de Guillebon H, Eng D: Retinal traction in vivo and post mortem. Arch Ophthalmol 1972, 87: 549-54.

${ }^{76}$ Gonin J: Le traitment de decollement retinien. Ann d'Oculist 1921, 158: 175-94.

${ }^{n}$ Foulds WS: Experimental retinal detachment. Trans Ophthalmol Soc UK 1963, 83: 153-70.

${ }^{78}$ Foulds WS: Experimental detachment of the retina and its effect on the intraocular fluid dynamics. Mod Probl Ophthalmol 1969, 8: 51-63.

${ }^{79}$ Machemer $\mathbf{R}$ and Norton EWD: Experimental detachment and reattachment I: methods, clinical picture and histology. Mod Probl Ophthalmol 1969, 8: 80-90.

${ }^{80}$ Adams ST: Retinal breaks in eye bank eyes. Arch Ophthalmol 1956, 55: 254-60.

${ }^{81}$ Okun E: Gross and microscopic pathology in autopsy eyes III. Retinal breaks without detachment. Am J Ophthalmol 1961, 51: 369-91.

${ }^{82}$ Barishak YR and Stein R: Retinal breaks without retinal detachment in autopsy eyes. Acta Ophthalmol 1972, 50: 147-59.

${ }^{83}$ Foulds WS: The vitreous in retinal detachment. Trans Ophthalmol Soc UK 1975, 95: 412-16.

${ }^{84}$ Pederson JE and Cantrill HL: The role of the vitreous in experimental retinal detachment. Invest Ophthalmol Vis Sci 1980, 19: ARVO supplement 46.

${ }^{86}$ Foulds WS: The pathogenesis of retinal detachment. Thesis for degree of MD. University of Glasgow 1964.

${ }^{87}$ Machemer R: The importance of fluid absorption, traction, intraocular currents and chorioretinal scars in the therapy of rhegmatogenous retinal detachment. Am J Ophthalmol 1984, 98: 681-93.

${ }^{88}$ Pederson JE and Toris CB: Experimental retinal detachment IX. Aqueous vitreous and subretinal protein concentrations. Arch Ophthalmol 1985, 103: $835-6$.

${ }^{89}$ Lindner K: Uber die Herstellung von modellen zu Modellversuchen der netzhaut abhebung. Klin Mbl Augenheilk 1933, 90: 289-300.

${ }^{90}$ Buchbaum G, Sternklar M, Litt M, Grunwald J, Riva CE: Dynamics of a n oscillating viscoelastic sphere: A model of the vitreous humor of the eye. Biorheology 1984, 21: 285-96.

${ }^{91}$ Foulds WS: Do we need a retinal pigment epithelium (or choroid) for the maintenance of retinal apposition. Br J Ophthalmol 1985, 69: 237-9.

${ }^{92}$ Foulds WS and Ikeda $\mathrm{H}$ : The effects of detachment of the retina on the induced and resting ocular potentials in the rabbit. Invest Ophthalmol Vis Sci 1966, 5: 93-108.

${ }^{93}$ Machemer R: Experimental retinal detachment in the owl monkey IV. Electronmicroscopy of the retina and pigment epithelium. Am J Ophthalmol 1968, 66: 396-410.

94 Johnson NF and Foulds WS: Observations on the retinal pigment epithelium and retinal macrophages in experimental retinal detachment. $\mathrm{Br}$ J Ophthalmol 1977, 61: 564-72.

${ }^{95}$ Machemer R, van Horn D, Aaberg TM: Pigment epithelial proliferation in human retinal detachments with massive epiretinal proliferation. Am J Ophthalmol 1978, 85: 181-91.

${ }^{96}$ Heath H, Beck T, Foulds WS: Chemical composition of subretinal fluid. BrJ Ophthalmol 1962, 46: 385-96.

${ }^{97}$ Weber JC and.Wilson FM: Biochemical studies of subretinal fluid II. Total protein and albumen of the subretinal fluid and blood serum in patients with retinal.detachment. Arch Ophthalmol 1963, 69: 363-9.

98 Chignell AH, Carruthers M, Rahi AHS: Clinical biochemical and immunoelectrophoretic study of subretinal fluid. Br J Ophthalmol 1971, 55: 52532.

${ }^{99} \mathrm{Himi}$ T: Total protein concentration of subretinal fluid in rhegmatogenous detachment of the retina. Acta Soc Ophthalmol Jpn 1975, 79: 1865-78.

100 Noell WK: Azide sensitive potential differences across the eye bulb. Am J Physiol 1952, 170: 21738. 
${ }^{101}$ Kroll AJ and Machamer R: Experimental retinal detachment in the owl monkey V. Electronmicroscopy of the reattached retina. Am J Ophthalmol 1966, 67: 117-30.

102 Zauberman H and Rosell FG: Treatment of retinal detachment without inducing chorioretinal lesions. Trans Am Acad Ophthalmol Otolaryng 1975, 79: 835-44.

${ }^{103}$ Chignell AH: Retinal detachment surgery without cryotherapy. Trans Ophthal Soc UK 1977, 97: 30-2.

${ }^{104}$ De Juan E, McCuen B, Tiedman J: Intraocular tamponade and surface tension. Surv Ophthalmol 1985, 30: 47-51.

$105 \mathrm{Ohm} \mathrm{J}$ : Uber die behandlung der netzhautablosung durch operativ entleemung der subretinal flusigheit und einspritzung von luft in den glaskorper. Graefe's Arch Clin Ophthalmol 1911, 79: $442-50$.

${ }^{106}$ Norton EWD: Intraocular gas in the management of selected retinal detachments. Trans Am Acad
Ophthalmol Otolaryng 1973, 77: 85-98.

${ }^{107}$ Cibis P, Becker B, Okun E, Canaan S: The use of liquid silicone in retinal detachment surgery. Arch Ophthalmol 1962, 68: 590-9.

${ }^{108}$ Scott JD: A rationale for the use of silicone. Trans Ophthalmol Soc UK 1977, 97: 235-7.

${ }^{109}$ Scott JD: Use of silicone oil in vitrectomised eyes. Dev Ophthalmol 1981, 2: 185-90.

${ }^{110}$ Scott JD: The use of viscoelastic materials in the posterior segment. Trans Ophthalmol Soc UK 1983, 103: 280-3.

111 Proliferative vitreoretinopathy: The silicone study group. Editorial. Am J Ophthalmol 1985, 99: 593-5.

${ }_{112}$ Lincoff H, Coleman J, Kreissig I, Richard G, Chang S, Wilcox L: The perfluorocarbon gases in the treatment of retinal detachment. Ophthalmology 1983, 90: 546-51.

${ }^{113}$ Taylor S and Folkman J: Proteinamin as an inhibitor of angiogenesis. Nature 1982, 297: 30712. 